\title{
Evolution of the Global Carbon Cycle and Climate Regulation on Earth
}

\author{
T.T. Isson ${ }^{1,2^{*}}$, N.J. Planavsky ${ }^{1 *}$, L.A. Coogan ${ }^{3}$, E.M. Stewart ${ }^{1}$, J.J. Ague ${ }^{1}$, E.W. Bolton ${ }^{1}$, \\ S. Zhang ${ }^{1}$, N.R. McKenzie ${ }^{4}$, L.R. Kump ${ }^{5}$

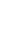 \\ ${ }^{1}$ Dept. of Geology and Geophysics, Yale University, New Haven, CT, USA \\ ${ }^{2}$ University of Waikato, Bay of Plenty, Tauranga, New Zealand \\ ${ }^{3}$ School of Earth and Ocean Sciences, University of Victoria, Victoria, BC, Canada \\ ${ }^{4}$ Dept. of Earth Sciences, University of Hong Kong, Pokfulam, Hong Kong, China, \\ ${ }^{5}$ Dept. of Geosciences, Pennsylvania State University, University Park, PA, USA \\ *Corresponding authors: terry.isson@gmail.com; noah.planavsky@yale.edu
} . .

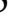

\section{Abstract}

The existence of stabilizing feedbacks on Earth is generally thought to be necessary for the persistence of liquid water and life. Earth's atmospheric composition appears to have adjusted to the gradual increase in solar luminosity over time, resulting in persistently habitable surface temperatures. With limited exceptions, the Earth system recovered rapidly from climatic perturbations. Carbon dioxide $\left(\mathrm{CO}_{2}\right)$ regulation via negative feedbacks within the coupled global carbon-silica cycles are classically viewed as the main processes giving

\section{Introduction}

Liquid water is essential for life as we know it (Dole, 1964). Although water is present on multiple bodies rise to climate stability on Earth. Here we review the long-term global carbon cycle budget and how the processes modulating Earth's climate system have evolved over time. Specifically, we focus on the relative roles that shifts in carbon sources and sinks have played in driving long-term changes in atmospheric $\mathrm{pCO}_{2}$. We make a case that marine processes are an important component of the canonical silicate weathering feedback, and have played a much more important role in $\mathrm{pCO}_{2}$ regulation than traditionally imagined. The weathering of marine sediments and off-axis basalt alteration are major carbon sinks. However, this sink was potentially dampened during Earth's early history when oceans had higher levels of dissolved silicon (Si), iron (Fe) and magnesium ( $\mathrm{Mg}$ ), and instead likely fostered more extensive reverse weathering-which in turn fostered higher ocean-atmosphere $\mathrm{CO}_{2}$. within our solar system, only one planet-Earth-has sustained liquid water at the surface for the majority of its history (Mojzsis et al., 2001; Wilde et al., 2001). Despite large changes in solar luminosity (Gough, 1981; Hoyle, 1957), ocean chemistry, and the rock cycle over time (Berner, 2004; Holland, 1984, 2002; Mackenzie and Garrels, 1971), processes within Earth's system have naturally regulated greenhouse gas levels so as to maintain relatively invariant planetary temperatures (Berner et al., 1983; Hart, 1978; Kasting, 1987; Sagan and Mullen, 1972). This climate stability has allowed for the persistent inhabitation and proliferation of complex life over billions of years, and is typically taken as strong evidence for the existence 
of stabilizing feedbacks on Earth (e.g., Berner and Caldeira, 1997; Kasting, 2019; Lovelock and Whitfield, 1982). Classically, climate regulation on Earth is viewed to be tied foremost to the regulation of atmospheric carbon dioxide $\left(\mathrm{CO}_{2}\right)$ levels, via processes controlling the rate of carbon removal from the oceanatmosphere system during terrestrial silicate weathering. Within this system, steady-state and transient variations in a range of carbon sources and sinks have been proposed to drive major changes in $p \mathrm{CO}_{2}$ and thus Earth's climate. Collectively, the robustness and character of Earth's climate regulating mechanisms have been proposed to play a significant role in governing its long-term habitable life span (Caldeira and Kasting, 1992; Li et al., 2009; Lovelock and Whitfield, 1982). In this light, a mechanistic understanding of Earth's climate feedbacks can help guide our views on planetary habitability beyond our solar system.

Here, we review key concepts and changes to traditional views of the long-term carbon cycle (section 2), its budget (section 3), and its evolution through time (section 4). Rather than providing an overview of all aspects of the long-term climate controls, we review the main processes leading to climate regulation and focus our discussion of potential deviations from the standard view (e.g., Berner, 2004).

\section{Climate Regulation Through the Carbon Cycle}

\subsection{Silicate Weathering}

Carbon enters the ocean-atmosphere reservoir through solid Earth degassing of $\mathrm{CO}_{2}$, and is lost through the sequestration of carbon as carbonate $\left(\mathrm{XCO}_{3}\right.$, here and elsewhere $\mathrm{X}$ represents a divalent cation, typically $\mathrm{Ca}^{2+}, \mathrm{Mg}^{2+}$ or $\mathrm{Fe}^{2+}$ ) or biomass $\left(\mathrm{CH}_{2} \mathrm{O}\right)$ (Fig. 1) (Chamberlin, 1899; Högbom, 1894; Urey, 1952). The pathways leading to the release and drawdown of carbon have long been recognized, and can be simply expressed as two fundamental reactions that highlight the inorganic (equation 1) and organic (equation 2) portions of the long-term carbon cycle.

This so-called Urey equation (equation 1 ) is the simplest description of the inorganic carbon cycle. In the

$$
\mathrm{XSiO}_{3}+\mathrm{CO}_{2} \leftrightarrow \mathrm{XCO}+\mathrm{SiO}_{2}
$$
forward (left to right) direction, the weathering of a silicate mineral $\left(\mathrm{XSiO}_{3}\right)$ is coupled to the removal of carbon as carbonate and silicon as chert $\left(\mathrm{SiO}_{2}\right)$. The reverse direction (right to left) illustrates $\mathrm{CO}_{2}$ degassing as a result of thermal decarbonation reactions during metamorphism.

$$
\mathrm{CO}_{2}+\mathrm{H}_{2} \mathrm{O} \leftrightarrow \mathrm{CH}_{2} \mathrm{O}+\mathrm{O}_{2}
$$

Equation 2 represent the organic portion of the carbon cycle. Here, the forward (left to right) direction describes carbon fixation, releasing oxygen $\left(\mathrm{O}_{2}\right)$ in the process, while the reverse (right to left) accounts for the oxidation of organic matter. Although water $\left(\mathrm{H}_{2} \mathrm{O}\right)$ is not the only electron donor (i.e., anoxygenic photosynthesis reactions exist), and similarly oxygen not the only oxidizing agent available, these represent 79 
It is important to note that the organic portion of the global carbon cycle is classically not viewed to have a substantial role in regulating climate stability given that oxygen sources and sinks are likely to balance each other due to the presence of strong negative feedbacks on atmospheric $\mathrm{O}_{2}$ (e.g., Berner, 2004; Laakso and Schrag, 2014; Ozaki et al., 2019). For instance, enhanced organic carbon production elevates free $\mathrm{O}_{2}$ and increases organic matter oxidation. However, there are exceptions to this view (e.g., France-Lanord and Derry, 1997; Galy et al., 2007; Galy et al., 2010).

The size of the ocean-atmosphere carbon reservoir at any given interval in Earth's history is controlled by a balance between rates of carbon input $\left(F_{i n}\right)$, and the ease with which carbon leaves the system (i.e., the efficiency of carbon sequestration for a given Earth state). All else being equal, an increase in degassing rates or an Earth environment more resistant to carbon removal (decrease weatherability or increase reverse weathering) will lead to an increase in atmospheric $\mathrm{pCO}_{2}$ (Fig. 1-3). Solid Earth processes (e.g., arc volcanism, mid ocean ridge spreading rates, and metamorphic decarbonation) govern the rates of new carbon being introduced (discussed in section 3.1). Carbon removal, on the other hand, involves two steps, first the conversion of $\mathrm{CO}_{2}$ to carbonate alkalinity $\left(\mathrm{HCO}_{3}{ }^{-}\right.$and $\left.\mathrm{CO}_{3}{ }^{2-}\right)$, and second the removal of carbonate alkalinity as carbonate rock $\left(\mathrm{XCO}_{3}\right)$. The ease to which $\mathrm{CO}_{2}$ is converted to carbonate alkalinity is determined by Earth's susceptibility to silicate weathering, a property commonly referred to as the 'weatherability' of Earth's surface environment (Fig. 2-3). Although the concept of weatherability is most commonly applied only to terrestrial silicate weathering, silicate weathering in the marine realm (in marine sediments and oceanic crust) ought to be included when referring to the weatherability of the Earth surface system as a whole. Numerous factors have been proposed to control Earth's surface weatherability in terrestrial environments, including crustal composition (lithology), tectonics (e.g., uplift rates, topography), continental configuration (paleogeography), hydrology and biological alteration (effect of land plants and soil biomass) (Kump and Arthur, 1997). On the other hand, the weatherability of the marine environment depends on the rate of formation of new oceanic crust, its bulk composition, abyssal sedimentation rate, and the saturation state of seawater with respect to silicate phases-all of which have likely evolved over the course of Earth's history.

There has been a longstanding debate about the locus of silicate weathering at Earth's surface (e.g., Kump et al., 2000). The view that silicate weathering occurred predominantly in terrestrial environments became the dominant view in the 1980's-1990's, but recent work has stressed the importance of the weathering of silicate minerals in the marine environment (Coogan and Gillis, 2018; Wallmann et al., 2008). Marine weathering can be categorized into two distinct marine environments and lithologies: (1) oceanic crust and (2) marine sediments (section 3.2.2).

\subsection{Reverse Weathering}

The formation of authigenic silicate minerals consumes alkalinity and generates acidity, a process classically referred to as reverse weathering (Garrels, 1965; Mackenzie and Garrels, 1966a; Sillén, 1961). As the name suggests, this process has, in essence, the opposite effect of silicate weathering: 


$$
3 \mathrm{X}^{2+}+2 \mathrm{H}_{4} \mathrm{SiO}_{4}+6 \mathrm{HCO}_{3}^{-} \leftrightarrow \mathrm{X}_{3} \mathrm{Si}_{2} \mathrm{O}_{5}(\mathrm{OH})_{4}+6 \mathrm{CO}_{2}+5 \mathrm{H}_{2} \mathrm{O}
$$

clay authigenesis (equation 3 from left to right) consumes dissolved cations, and converts carbonate alkalinity back into $\mathrm{CO}_{2}$. This $\mathrm{CO}_{2}$ now has to facilitate another round of silicate weathering (equation 1 ) before it can be removed as carbonate rock. Reverse weathering in essence recycles carbon within the ocean-atmosphere reservoir. This process makes carbon export from the system less efficient by increasing the amount of silicate weathering required to sequester an equal amount of carbon relative to a system with less extensive reverse weathering (Isson and Planavsky, 2018). Thus, all else being equal, an increase in reverse weathering will elevate the amount of carbon in the ocean-atmosphere reservoir and thus baseline $\mathrm{pCO}_{2}$ levels (Fig. 1, 2). It is important to note, however, that although reverse weathering is a source of $\mathrm{CO}_{2}$, it is not a source of new carbon and thus does not alter the total steady-state flux of carbon entering (or leaving) the ocean-atmosphere system. Reverse weathering does, however, act as a net sink for ocean alkalinity. Similar to silicate weathering, the process of reverse weathering encompasses an extensive suite of reactions-reflecting the diversity of clay mineral species and flexible mineral stoichiometries that can form under different chemical conditions. Clays in the marine realm can form directly from dissolved constituents or through cation enrichment of pre-existing clays.

\subsection{Mass Balance and Stabilizing Feedbacks}

The mass of the ocean-atmosphere carbon reservoir is small compared to that of geologic reservoirs, implying that short-term mass imbalances can easily occur. In a classic thought experiment, Berner and Caldeira (1997) highlighted with a simple box model that small carbon imbalances will very rapidly (on $<10^{6}$ years) trigger $\mathrm{CO}_{2}$ runaway into extreme icehouse or hothouse conditions (Fig. 4). In other words, it is not possible for chemical weathering rates to be substantially out of balance with the supply of $\mathrm{CO}_{2}$ from volcanic and metamorphic sources for extended intervals without catastrophic consequences. While rapid temperature shifts have been observed throughout Earth's history, these occurrences are rare, and where they have been observed to take place, Earth's system has without failure responded by re-establishing relatively clement conditions. In other words, with limited exceptions-foremost the Snowball Earth Events (Hoffman et al., 2017) - none of Earth's climate perturbations were a threat to sustained habitability. This suggests that although mass imbalance may persist on the short term $\left(<10^{6}\right.$ years), the total amount of carbon removal from the ocean-atmosphere reservoir $\left(F_{\text {out }}\right)$ must be nearly equal to new carbon input $\left(F_{\text {in }}\right)$ in the long term ( $>10^{6}$ years). It is therefore reasonable to assume that negative or stabilizing feedbacks must exist for a system to consistently achieve mass balance. At the core of these feedbacks is a link between the rate-limiting step of $\mathrm{CO}_{2}$ drawdown and $\mathrm{CO}_{2}$ levels. There are three stabilizing feedbacks that have been commonly discussed (Fig. 5):

(1) Terrestrial silicate weathering feedback. The view that the terrestrial silicate weathering feedback is the main factor regulating temperatures on Earth has been deeply entrenched in our view of climate stability on Earth. The basic idea of this feedback is that any increases in $\mathrm{CO}_{2}$ lead to 
increased surface temperatures, acceleration of the hydrological cycle, and larger fluxes of silicate chemical weathering, leading to greater $\mathrm{CO}_{2}$ removal from the ocean-atmosphere system through continental weathering (Berner et al., 1983; e.g., Urey, 1952; Walker et al., 1981).

(2) Marine silicate weathering feedback. Recent work has highlighted that rates of silicate mineral dissolution within mafic oceanic crust are sensitive to bottom-water temperatures, essentially establishing a negative feedback with $\mathrm{CO}_{2}$ given that sea surface and bottom water temperatures are intimately coupled (Brady and Gíslason, 1997; e.g., Coogan and Dosso, 2015). Silicate dissolution within marine sediments has also been noted to contribute to global alkalinity fluxes (Solomon et al., 2008; Wallmann et al., 2008). Here, release of $\mathrm{CO}_{2}$ during organic matter decomposition drives silicate mineral dissolution (e.g., Aloisi et al., 2004). Additionally, the production of dissolved organic humic and fulvic acid anions that complex cations (e.g., $\mathrm{Al}^{3+}$ ) is proposed to enhance mineral dissolution through further undersaturation of primary silicate phases. Rates of primary productivity (and the myriad factors affecting water column organic carbon remineralization) have therefore been proposed to exert a control on weathering rates (Wallmann et al., 2008). There are links between organic matter delivery to sediments and temperature-however these associations have not yet been demonstrated to clearly give rise to a stabilizing feedback. Direct bottom-water temperature and $\mathrm{pH}$ controls on mineral dissolution rates ought to establish a negative feedback with atmospheric $\mathrm{CO}_{2}$ levels as well, but the chemistry of porewaters (and waters within fractured oceanic crust) can evolve significantly with depth, and do not necessarily reflect surface water conditions.

(3) Reverse silicate weathering feedback. The flux of $\mathrm{CO}_{2}$ to the ocean-atmosphere system derived from reverse weathering is sensitive to marine $\mathrm{pH}$ conditions and thus $\mathrm{pCO}_{2}$ (Isson and Planavsky, 2018; Sillén, 1961, 1967). This link results in a stabilizing climate feedback. For instance, an increase in $\mathrm{pCO}_{2}$ levels (decrease in marine $\mathrm{pH}$ ) will lead to decreased reverse weathering, in turn acting to lower $\mathrm{pCO}_{2}$ levels. Because increasing temperatures will act to elevate rates of reverse weathering (reactions are more rapid at higher temperatures), the $\mathrm{pH}$ kinetic effect must outweigh the temperature effect. This sensitivity to $\mathrm{pH}$ appears to be the case in the most detailed clay experimental work done thus far (e.g., Tosca et al., 2016; Tosca et al., 2011), though it should be noted that there is a dearth of clay kinetic data.

All three of these stabilizing feedbacks operate together as a unified global silicate weathering feedback, although with varied response times for each individual feedback. With a shift away from a stable state in the carbon cycle and climate (e.g., with a change in $\mathrm{CO}_{2}$ outgassing rates) the change in atmospheric $\mathrm{pCO}_{2}$ is set by the strength of the global silicate weathering feedback. A stronger silicate weathering feedback yields a smaller change in $\mathrm{pCO}_{2}$ level for an equivalent forcing. Controls on the strength of the silicate weathering feedback traditionally include the amount of fresh silicate material exposed at Earth's surface undergoing water-rock interactions, the composition of Earth's weatherable shell, and the role of the terrestrial 
chemistry-and in particular marine Si concentrations-will also play a role in controlling the strength of the

201 global silicate weathering feedback.

\section{Global Carbon Cycle Budget}

\section{$204 \quad 3.1$ Carbon Sources}

\subsubsection{Modern Degassing Estimates}

$\mathrm{CO}_{2}$ is released from the solid Earth into surface reservoirs via both volcanic and metamorphic processes (equation 1, from right to left). Volcanic fluxes have long been considered the primary contribution to global degassing, and, as such, there is a substantial body of work dedicated to constraining their magnitudes. Modern mid-ocean ridge volcanism is estimated to contribute $\sim 1.0$ to $\sim 5.0 \mathrm{Tmol} \mathrm{CO}_{2} \mathrm{yr}^{-1}$ (for reference 1 Tmol C is approximately 0.012 Pg C) (Chavrit et al., 2014; Dasgupta and Hirschmann, 2006, 2010; Hirschmann, 2018; Le Voyer et al., 2017; Marty and Tolstikhin, 1998; Matthews et al., 2017; Saal et al., 2002). While this range is quite significant, it is possible that this upper limit remains conservative, given the lack of consideration of other factors such as bubble loss (e.g., Chavrit et al., 2014). Further, explosive volcanism along ridges provide evidence for melt inclusions with extremely high $\mathrm{CO}_{2}$ content, suggesting that the $\mathrm{CO}_{2}$ content of MORB may be much more heterogeneous than previously thought (Helo et al., 2011; Ilyinskaya et al., 2018).

Arc volcanic degassing estimates range from $\sim 1.5$ to $~ 3.2 \mathrm{Tmol} \mathrm{CO}_{2} \mathrm{yr}^{-1}$ (Dasgupta and Hirschmann, 2010; Hilton et al., 2002; Marty and Tolstikhin, 1998). However, there is work suggesting that arc magmas may be more $\mathrm{CO}_{2}$-rich than previously thought, and that the arc volcanic $\mathrm{CO}_{2}$ flux may be correspondingly higher (Blundy et al., 2010). A large portion of the carbon emitted by these volcanoes may be derived from reworking of crustal carbonate rocks in the upper plate (Mason et al., 2017). Further, metamorphism in contact aureoles around magmatic intrusions also drives decarbonation reactions (D'Errico et al., 2012; Lee et al., 2013). We are not aware of any quantitative estimate of the global contact metamorphic flux (flux estimates from observations of atmospheric plumes above volcanoes should integrate this $\mathrm{CO}_{2}$ with magmatic $\mathrm{CO}_{2}$ ). For example, Nesbitt et al. (1995) estimate that 1.5 to $7.8 \mathrm{Tmol} \mathrm{CO}_{2} \mathrm{yr}^{-1}$ were released by Cenozoic contact metamorphism in the North American Cordillera. Lee et al. (2013) suggest that contact metamorphism in continental arcs has been a major control on atmospheric $\mathrm{CO}_{2}$ throughout the Phanerozoic. Intraplate volcanism is less well-studied, but Dasgupta and Hirschmann (2010) suggest a range of $\sim 0.12$ to $\sim 3.0 \mathrm{Tmol} \mathrm{CO}_{2} \mathrm{yr}^{-1}$ degassed from ocean island basalts and Lee et al. (2013) calculate a flux of $\sim 0.8$ to $\sim 2.4 \mathrm{Tmol} \mathrm{CO}_{2} \mathrm{yr}^{-1}$ from continental rift volcanism.

Metamorphic decarbonation in mixed carbonate-silicate rocks has been shown to be an equally important source of $\mathrm{CO}_{2}$ (Bickle, 1996; Kerrick and Caldeira, 1993, 1999; Kerrick and Caldeira, 1998; Stewart et al., 2019). While it has been suggested that metamorphic decarbonation is negligible except at very high temperatures (e.g., Dasgupta, 2013), these calculations ignore the critical effect of fluid infiltration. A rock 
decarbonate at much lower temperatures (Ferry, 1988), and may release more than $500 \%$ more $\mathrm{CO}_{2}$ than metamorphism of the same rock in a closed system (Stewart and Ague, 2018). The extent to which the Urey reactions can work in reverse depend on the supply of Si either from impurities in the rock or transported in a fluid (Ague, 2003). As noted by Stewart and Ague (2018), multiple independent calculations of degassing during regional metamorphism agree on an area-normalized flux of $\sim 0.5 \times 10^{6}$ to $\sim 7 \times 10^{6} \mathrm{~mol} \mathrm{CO}_{2} \mathrm{yr}^{-1} \mathrm{~km}^{-2}$ (Becker et al., 2008; Chiodini et al., 2000; Kerrick and Caldeira, 1998; Skelton, 2011). These studies estimate the flux via both thermodynamic modeling of metamorphism at depth (Kerrick and Caldeira, 1998; Skelton, 2011; Stewart and Ague, 2018) and surface measurements of degassing in modern mountain belts (Becker et al., 2008; Chiodini et al., 2000), suggesting that most of the devolatilized $\mathrm{CO}_{2}$ does escape to the surface environment. Multiplying this areal flux by the area of present-day orogenesis $\left(\sim 10^{6} \mathrm{~km}^{2}\right.$, dominated by the Himalayas) (Becker et al., 2008), we arrive at a modern regional metamorphic flux of 0.5 to $7.0 \mathrm{Tmol} \mathrm{CO}_{2} \mathrm{yr}^{-}$ 1.

Carbon dioxide is also released via metamorphic decarbonation in subducting oceanic crust. Based on closed-system thermodynamic modeling, it was believed that this decarbonation was minimal and that most $\mathrm{CO}_{2}$ is retained within the subducting slab to depths of more than $\sim 100 \mathrm{~km}$ (Dasgupta and Hirschmann, 2010; e.g., Kerrick and Connolly, 2001). However, recent work by Kelemen and Manning (2015) suggests that subduction zones are highly inefficient at shuttling carbon into the convecting mantle. There are several possible explanations for this discrepancy. As with regional metamorphism, subduction-related decarbonation may also be facilitated by fluid infiltration (Gorman et al., 2006), thus accounting for the presence of a water-bearing fluid increases flux estimates. In addition, congruent dissolution of carbonate minerals during subduction may release even more $\mathrm{CO}_{2}$ from the slab (Ague and Nicolescu, 2014). Some amount of $\mathrm{CO}_{2}$ is also released during partial melting of carbonate-bearing rocks (e.g., Duncan and Dasgupta, 2014; Grassi and Schmidt, 2011; Poli, 2015). Furthermore, mechanical processes such as sediment diapirism may transfer $\mathrm{CO}_{2}$ from the subducting slab to the overriding plate (Kelemen et al., 2003). In an apparent contradiction to the "what goes down mostly comes back up" world view (Kelemen and Manning, 2015), global geochemical arguments (specifically relating to $\mathrm{CO}_{2} / \mathrm{Ba}$ ratios) may indicate that $35-80 \%$ of outgassed $\mathrm{CO}_{2}$ must be returned to the mantle, presumably via subduction (Hirschmann, 2018). Moreover, $\mathrm{CO}_{2}$ released via decarbonation and dissolution may be reincorporated into the slab by carbonation reactions driven by migrating fluids (e.g., Piccoli et al., 2016; Scambelluri et al., 2016). Finally, the amount of $\mathrm{CO}_{2}$ and organic carbon delivered to subduction zones varies considerably in both space and time (Plank and Manning, 2019). The storage of $\mathrm{CO}_{2}$ in the lithosphere is a major uncertainty in both models. Thus the efficiency of $\mathrm{CO}_{2}$ subduction remains an area of ongoing research and debate, and more work is needed to reconcile these disparate models.

Once released, $\mathrm{CO}_{2}$ from the slab may escape to the surface as part of the arc volcanic flux or it may form a separate, diffuse $\mathrm{CO}_{2}$ flux. Kelemen and Manning (2015) estimate this diffuse subduction flux as $\sim 0.3$ to $\sim 1.0$ $\mathrm{Tmol} \mathrm{CO}_{2} \mathrm{yr}^{-1}$, but go on to speculate that it may be much higher. It is also probable that some slab-derived $\mathrm{CO}_{2}$ is precipitated in the overlying crust for long-term storage (up to $3.9 \mathrm{Tmol} \mathrm{CO}_{2} \mathrm{yr}-1$ from Kelemen and Manning (2015)), rather than being released to the surface. The proportion of $\mathrm{CO}_{2}$ that follows each of these paths remains as a major uncertainty in our understanding of global carbon cycling. 


\subsection{Carbon Sinks}

\section{$281 \quad$ 3.2.1 Terrestrial Weathering}

282 As outlined above, the weathering of silicate minerals in terrestrial settings contributes alkalinity to the marine environment. Carbonate weathering coupled to the eventual precipitation of carbonate rock from seawater, however, has no long-term net effect as a source or sink of carbon unless these fluxes are out of balance-implying a change to the composition of Earth's sedimentary reservoir. Further, changes to the composition of the upper continental crust have been suggested to influence the weatherability of Earth's surface and hence atmospheric $\mathrm{pCO}_{2}$ (Gaillardet et al., 1999; Hartmann et al., 2014; e.g., Suchet et al., 2003). Today, the upper continental crust exposes 65-71\% sedimentary rock (Hartmann and Moosdorf, 2012; Hartmann et al., 2014; Li, 2000; Suchet et al., 2003) (Fig. 6). The non-sedimentary fraction comprises $\sim 16 \%$ basic (e.g., basalts and gabbros), $8 \%$ intermediate, and $26 \%$ acidic (e.g., rhyolites and granites) igneous rocks, with metamorphic rocks making up the remaining 50\% (Hartmann et al., 2014). On average, the main components of granite are K-feldspar, sodic plagioclase and quartz (in roughly equal proportions), while basalts are high in calcic plagioclase ( $60 \%)$, pyroxene $(\sim 30 \%)$ and olivine ( $10 \%)$ (Mason and Moore, 1982). The sedimentary reservoir comprises roughly $51 \mathrm{wt}$ \% shale, $23 \mathrm{wt}$ \% sandstone, $25 \mathrm{wt} . \%$ carbonate and $1 \%$ evaporate $(\mathrm{Li}, 2000)$. It should be noted that the metamorphic rock classification is compositionally broad (i.e., can refer to a rock of virtually any composition), and basically describes any rock with a crystalline texture interpreted to have been subject to elevated pressure and/or temperature sometime after initial formation of the rock (Hartmann and Moosdorf, 2012). Metamorphic rocks are $~ 90 \%$ metasedimentary, with meta-igneous rocks comprising the remaining 10\% (Ronov et al., 1990), which bolsters the case that the Earth's weatherable shell is dominated by sedimentary (and metasedimentary) rocks (e.g., Bluth and Kump, 1994; Bluth and Kump, 1991).

In the modern oceans, calcium ( $\mathrm{Ca}$ ) is the main cation involved in the removal of carbon as carbonate. Shales and silts are however, on average, depleted in Ca relative to crystalline rocks. This does not mean that the weathering of shales and silts does not contribute to the formation of carbonate rock. Instead, the weathering of shales and silts has to be linked to either: (1) the formation of dolomite (Ca-Mg-carbonate) which, although uncommon today, was far more prominent during other intervals in Earth's history when dolomite was the dominant carbonate phase (Lowenstein et al., 2003); and/or (2) hydrothermal exchange of $\mathrm{Mg}$ (derived from shales or silt weathering) for Ca.

Tremendous effort has been put into understanding the factors controlling terrestrial silicate weathering rates (e.g., Brantley, 2008; Kump et al., 2000; Li et al., 2017). Arguments center on the relative importance of soil biome, temperature, denudation rates, tectonics, and hydrologic controls on chemical weathering: this debate is nuanced, even though the basic idea of how each one influences weathering is straightforward. Mineral dissolution rates increase with temperature, organic acid levels, denudation, and increased water flux through the weathering zone (e.g., Brantley, 2008; Chen and Brantley, 1997; Maher and Chamberlain, 2014). On a broad scale, if denudation rates are higher there is more fresh material to weather and thus silicate weathering rates are likely to increase. Similarly, if more water is fluxed through the 
weathering zone, minerals will be further from equilibrium and dissolution rates will increase (Maher and Chamberlain, 2014).

\subsubsection{Transport Versus Weathering Limitation}

There are two end member views for thinking about controls on chemical silicate weathering in terrestrial environments-supply-limited and weathering-limited regimes (Kump et al., 2000; Stallard and Edmond, 1981, 1983; Stallard, 1985). In a supply-limited system, rates of $\mathrm{CO}_{2}$ drawdown are limited by the amount of material exposed to weathering, and changes to atmospheric $\mathrm{pCO}_{2}$ levels (and surface temperature) do not influence weathering rates. In this end-member view, it is the extent of tectonic uplift and hence the supply of fresh material that regulates atmospheric $\mathrm{pCO}_{2}$ levels-essentially negating the terrestrial silicate weathering feedback. In contrast, a weathering-limited regime has an 'excess' of material available for water-rock interactions, and rates of $\mathrm{CO}_{2}$ consumed through silicate weathering are limited by both temperature and the supply of $\mathrm{CO}_{2}$ (coupled to factors such soil $\mathrm{pH}$ and mineralogy). In this world view, there is a strong terrestrial silicate weathering feedback, where an increase in atmospheric $\mathrm{CO}_{2}$ levels and global temperature will increase $\mathrm{CO}_{2}$ delivery to and consumption within the weathering realm.

There is compelling evidence to suggest that global silicate weathering today is not supply-limited. Global datasets indicate that an increase in runoff is met by an increase in silicate weathering rates (e.g., Maher and Chamberlain, 2014), implying that more intense hydrology always increases $\mathrm{CO}_{2}$ neutralization, and so Earth as a whole cannot be supply-limited (Fig. 7). Quantifying the extent of physically eroded but chemically unweathered material accumulating in river deltas

In addition, the expression of immature soils rich in primary silicate phases at Earth's surface, particularly in highland areas, represent an excess of silicate material available for weathering. Furthermore, geochemical and mineralogical evidence suggest that shifts in global temperatures across hyperthermal events are often coupled to accelerated rates of silicate weathering (e.g., Penman, 2016; Von Strandmann et al., 2013).

Earth's system as a whole is generally viewed to sit somewhere in between these two end member regimes, with some environments sitting closer to one end member than another denoting local scale heterogeneity to Earth's weatherable environment. The Amazon watershed, for instance, sits closer to the supply-limited end member regime relative to the Great Himalayan Watershed (Hartmann et al., 2014). Such supply-limited environments are characterized by thicker, more mature (chemically depleted) soils largely devoid of primary silicate minerals (e.g., feldspars, olivine, hornblende), and are composed mostly of secondary mineral phases (e.g., clay minerals and oxides) depleted in soluble cations $\left(\mathrm{Ca}^{2+}, \mathrm{Mg}^{2+}, \mathrm{Na}^{+}\right.$and $\left.\mathrm{K}^{+}\right)$. In contrast, watersheds that sit closer to the weathering limited environment have a less mature, higher primary silicate mineral content (less chemically depleted).

The globally averaged weathering state has the potential to slide between these two end member regimes. In particular, there are intervals in Earth's history where Earth as a whole is suggested to have shifted 
towards the supply limited end member regime. These include the (1) end-Permian to early Triassic interval where the amount of $\mathrm{CO}_{2}$ injected into the ocean-atmosphere system is suggested to have come close to "exhausting" Earth's weatherable shell so as to provide an explanation for the delayed climate recovery during this interval (Kump, 2018) and (2) end-Cretaceous through early Eocene time periods (Misra and Froelich, 2012). It is perhaps important to note that although Earth's system as a whole is not supply-limited, this does not mean that Earth's climate system is insensitive to tectonic changes. All else being equal, an increase in tectonic uplift rates will elevate both weathering fluxes globally, and the weatherability of Earth's surface environment and thus the strength of the silicate weathering feedback (e.g., Caves et al., 2016; Kump and Arthur, 1997; Rugenstein et al., 2019; Zhang and Planavsky, 2019). Rates of uplift bring fresh silicate material into the weatherable portion of Earth's surface environment. In essence, an increase in uplift will decrease the integrated maturity of soil profiles globally.

\subsubsection{Terrestrial Sources of Acid for Weathering}

372 Continental weathering reactions are tied to the neutralization of $\mathrm{CO}_{2}$. Carbon dioxide is supplied predominantly through direct diffusion between the atmosphere and terrestrial fluids, the partitioning of $\mathrm{CO}_{2}$ into rainwater, and/or the supply and oxidation of organic matter in soils (e.g., through respiration) (Fig. 8). An increase in the biological supply of $\mathrm{CO}_{2}$ to the soil environment has the potential to alter the $\mathrm{pH}$ of soil porewater and thus mineral dissolution rates. On this basis, there have been arguments concerning the role that biology (microbiota and vascular plants) has played in altering both weathering rates and the weatherability of Earth's terrestrial environment, and in turn atmospheric $\mathrm{pCO}_{2}\left(\right.$ and $\left.\mathrm{O}_{2}\right)$ levels.

Perhaps most notably, it has been commonly proposed that the emergence and diversification of vascular land plants during the Silurian and Devonian ( $\sim 20$ million years ago) could have led to a drawdown of $\mathrm{pCO}_{2}$ levels through a transient enhancement of terrestrial weathering rates (Algeo et al., 1995; Berner, 1997, 1998). It is suggested that this transient weathering enhancement could occur through several mechanisms including; (1) increasing water retention in soils; (2) root and heterotrophic respiration of plant debris; (3) production of organic acids from plant roots; (4) root physical erosion; and (5) stabilization of soils (Berner, 1992; Drever, 1994; Gibling and Davies, 2012; Griffiths et al., 1994; Winnick and Maher, 2018). Support for this argument typically involve calling upon both laboratory (e.g., Quirk et al., 2015) and field data (e.g., Bormann et al., 1998; Moulton and Berner, 1998) that indicate enhanced chemical weathering in systems with land plants as compared to barren surfaces or ones covered with moss/lichen (i.e., no significant root penetration) (Lenton, 2001). In contrast, recent steady-state carbon cycle modeling work indicate that the rise of land plants potentially decreased (instead of increase) silicate weathering rates, and that any drop in $\mathrm{CO}_{2}$ levels was instead linked to an increase in the strength of the silicate weathering feedback (D'Antonio et al., 2019).

The link between vascular plants and atmospheric $\mathrm{CO}_{2}$ levels through the Paleozoic has, however, remained contentious for several reasons. First, the earlier evolving bryophytes (liverworts; in the Ordovician) (Quirk et al., 2015) have also been shown to accelerate weathering rates, and direct comparison of these with the 
these biologically enhanced weathering rates derived from short lived experiments ('instantaneous' relative to the time scale of soil formation) into long-term global biogeochemical cycle models that operate on the multi million-year time scales has the potential to drastically overestimate the integrated weathering rate. Silicate weathering rates decrease as a soil horizon matures given that primary phases become more depleted (Fig. 9). In areas with limited denudation, integrated or long-term weathering rates with and without land plants will be closer than the observed initial difference. Although both field and experimental data that highlight biotic enhancement of weathering (sometimes by several orders magnitude), rate enhancements at such high levels are likely not sustainable on longer time scales. When weathering fluxes are integrated on time scales similar to or longer than that of soil formation (and maturation), the net weathering effect with or without vascular plants become significantly less or even indistinguishable (Fig. 9). This framework was put into question by Keller and Wood (1993), where they used a reactive transport model to make a case that vascular plants are likely not required to maintain low soil $\mathrm{pH}$. Instead, they propose that terrestrial chemical weathering rates were more likely equally intense before and after the rise of vascular plants. Specifically, they posit that because $\mathrm{CO}_{2}$ loss from soils is a slow process, only a small amount of microbial soil respiration is required to maintain high $\mathrm{CO}_{2}$ (low pH) porewaters. On the empirical side, terrestrial cyanobacterial biofilms have been found to significantly increase silicate weathering rates (Seiffert et al., 2014).

Sulfuric acid $\left(\mathrm{H}_{2} \mathrm{SO}_{4}\right)$ derived from the oxidation of pyrite:

$$
\mathrm{FeS}_{2}+3.75 \mathrm{O}_{2}+3.5 \mathrm{H}_{2} \mathrm{O} \leftrightarrow 2 \mathrm{H}_{2} \mathrm{SO}_{4}+\mathrm{Fe}(\mathrm{OH})_{3}
$$

also accounts for a portion of the acid that facilitates weathering in the terrestrial environment ( 5\% of silicate dissolution and 10\% of carbonate dissolution) (Brantley, 2008; Torres et al., 2014). Iron oxidation likely accounts for a smaller portion of the acid that facilitates weathering, although this flux is poorly constrained.

\subsubsection{Groundwater Alkalinity Fluxes}

There have been extensive studies of river input to the ocean and its influence on global biogeochemical cycling (e.g. Berner \& Berner, 2012; Gaillardet et al., 1999; Meybeck, 1987; Milliman \& Farnsworth, 2011), but we still have a relatively nascent understanding of groundwater discharge and element fluxes to the ocean (Taniguchi et al., 2002). However, there is mounting evidence that groundwater discharge is a critical component of the water and nutrient budget in the land-ocean system (e.g., Burnett et al., 2003; Kwon et al., 2014; Moore et al., 2008). Further, there is evidence that groundwater plays a significant role in coastal ecosystem evolution (Moosdorf \& Oehler, 2017; Paytan et al., 2006). Groundwater contains, on average, significantly higher bicarbonate concentrations than overlying surface waters, indicating that weathering occurs not only in soil horizons but also deeper within the crust (Zhang and Planavsky, in press). In terms of the global carbon cycle, continental groundwater discharge serves as a pathway for dissolved carbon fluxes previously underappreciated carbon sink (Zhang and Planavsky, in press). 
Groundwater discharge to the ocean is usually called submarine groundwater discharge (SGD), which is defined as "any and all flow of water on continental margins from the seabed to the coastal ocean" (Burnett et al., 2003). Since groundwater flow in a coastal region can be driven by both terrestrial and marine forces, SGD therefore comprises two sources-terrestrially derived fresh water (fresh SGD) that is originally produced by rainwater infiltration on land, and modified seawater (saline SGD) that penetrates through the land-ocean interface and is recirculated back to the ocean. When these two sources are mixed, SGD is called mixed or brackish SGD. There are several approaches to estimate SGD, depending on the spatial extent of interest. On a local scale, seepage meters can measure mixed SGD at specific locations directly. On a regional scale, chemical tracers (e.g. radium and radon) can be used to quantify the mixed SGD fluxes integrated over continental shelves. On a global scale, hydrological modeling and water balance methods can both be applied for estimation of fresh SGD (Mulligan and Charette, 2009; Taniguchi, 2002). Unfortunately, flux estimates from these approaches are typically significantly different (see discussion in Zhang and Planavsky, 2019)

Compared with river systems that are well gauged and monitored throughout the world, direct quantification of global SGD is extremely difficult since it mainly occurs as unseen diffusive flow on continental margins and varies significantly over temporal and spatial scales. The installation of seepage meters lacks global coverage, and up-scaling of seepage measurement remains a challenge. The chemical tracer approach seems to be more fruitful in quantifying large-scale SGD. Using ${ }^{228} \mathrm{Ra}$ as a tracer, (Moore et al., 2008) concluded that the magnitude of SGD in coastal region of the Atlantic Ocean is comparable to the corresponding river flux. Combining global observations of ${ }^{228} \mathrm{Ra}$ and an inverse model, (Kwon et al., 2014) argued that the SGD along the coastlines between $60^{\circ} \mathrm{S}$ and $70^{\circ} \mathrm{N}$ is around 3 times greater than the river discharge. After correcting the salinity effect, (Cho and Kim, 2016) stated that instead of 3 to 4 times, global SGD is approximately 1-1.5 times the river discharge. In terms of element fluxes, it is reported by Cho et al. (2018) that dissolved inorganic nitrogen, phosphorus, and silicon derived from SGD are comparable with the river fluxes to the global ocean.

For dissolved inorganic carbon (DIC) and alkalinity, several studies argued that SGD-derived fluxes exceed regional river input and in some cases are one order of magnitude larger (Liu et al., 2014; Stewart et al., 2015). It should be noted that a large portion of SGD is thought to belong to saline SGD (Kwon et al., 2014; Taniguchi et al., 2006). Consequently, fresh SGD might be significantly less than river discharge (Taniguchi, 2002), and the element flux (including dissolved carbon) derived from fresh SGD might be diminished. Given the fact that DIC concentration in groundwater is typically higher than rivers in the same region (Stewart et al., 2015; Szymczycha and Pempkowiak, 2015), even a relatively small magnitude of fresh SGD could potentially make a non-negligible contribution to the total dissolved carbon flux to the ocean. It was recently estimated that between $20 \%-250 \%$ of chemical silicate weathering globally occurred in groundwaters (Zhang and Planavsky, in press). This estimate highlights foremost that large uncertainties exist for estimating fresh SGD and the extent of groundwater mediated silicate weathering. However, it has 


\subsubsection{Weathering of Marine Sediments}

481 The emerging perspective from recent studies is that silicate mineral dissolution within marine environments contributes to global alkalinity and thus carbon sequestration, suggesting that the terrestrial to marine transition is better viewed as a continuum rather than two distinct environments.

The physical erosion of rocks in terrestrial environments delivers detrital silicate materials (e.g., feldspar, olivine, pyroxene, volcanic ash, clays) to the marine environment where they can make up a significant portion of marine sediments. Here, recent work provides compelling geochemical evidence for potentially substantial rates of silicate dissolution in marine sediments (e.g., Kim et al., 2016; Maher et al., 2004; Maher et al., 2006; Scholz et al., 2013; Solomon et al., 2008; Wallmann et al., 2008). This is perhaps unsurprising as seawater and porewaters are generally undersaturated with respect to primary silicate minerals, and thus their dissolution plays a role in buffering pore fluid $\mathrm{pH}$ and chemistry. Geochemical evidence for marine weathering deviates from the traditional framework, which specifies that silicate mineral dissolution is largely limited to terrestrial environments. Through the same Urey reaction pathway invoked for continental silicate weathering (equation 1), the generation of alkalinity and cations during the weathering of marine sediment plays a potentially large role in global carbon sequestration when coupled to carbonate formation.

Techniques used to fingerprint silicate mineral dissolution within sedimentary systems include the application of isotope tracers (e.g., ${ }^{87} \mathrm{Sr} /{ }^{86} \mathrm{Sr}$, (Kim et al., 2016); ${ }^{234} \mathrm{U} /{ }^{238} \mathrm{U}$ (Maher et al., 2004; Maher et al., 2006)) and the identification of "anomalous" alkalinity or cation (e.g., $\mathrm{Mg}^{2+}$ and $\mathrm{Ca}^{2+}$ ) fluxes (Scholz et al., 2013; Solomon et al., 2008; Wallmann et al., 2008) within porewaters. Unexpectedly high alkalinity fluxes can be used as tracers for silicate weathering by first establishing background in situ porewater alkalinity levels through the application of diagenetic reaction transport modeling (e.g., Scholz et al., 2013; Solomon et al., 2008; Wallmann et al., 2008).

Silicate dissolution has been observed to take place throughout the sediment column within virtually all redox zones (oxic, suboxic, sulfidic and methanic). Further, silicate weathering rates have been observed to evolve with depth into the sediment pile and laterally between depositional environments. Both the availability of primary silicate minerals and porewater chemistry ultimately determine the rate of silicate dissolution. Silicate mineral availability varies depending on the local tectonic regime, bottom water temperature, and proximity to the shoreline. For instance, in situ weathering rates have been observed to vary by up to 4 orders in magnitude between the deep sea site ODP Site 984 in the North Atlantic, and slope sediments on the Sakhalin Slope, Sea of Okhotsk (Maher et al., 2006; Wallmann et al., 2008). Critically, porewater chemistry evolves with depth, most notably between redox zones tied to the oxidation of organic matter, and has the potential to alter the saturation state (and thus dissolution rate) of silicate phases. Some of the most rapid rates of silicate weathering have been observed to occur within the methanogenic zone of

516 the sediment pile (Wallmann et al., 2008). On the basis that methanogenesis is responsible for the 517 generation of $\sim 5-20 \mathrm{Tmol} \mathrm{yr}^{-1}$ of $\mathrm{CO}_{2}$ (and an equal amount of $\mathrm{CH}_{4}$ ) globally (Hinrichs and Boetius, 2002; 518 Reeburgh, 1993; Wallmann et al., 2012) and the assumption that all this $\mathrm{CO}_{2}$ is neutralized through silicate 519 mineral dissolution in marine sediments (Wallmann et al., 2008), it has been proposed that roughly a third 
of this alkalinity is precipitated in marine sediments as authigenic carbonate, and the rest fluxed into overlying seawater (Wallmann and Aloisi, 2012; Wallmann et al., 2008).

\subsubsection{Weathering of Oceanic Crust}

524 Oceanic crust that is continually accreted along the global mid-ocean ridge network covers more than half of Earth's surface. The uppermost layer of this crust is made up of high-porosity and permeability lavas through which seawater continually circulates. The difference between measured conductive heat flow at the seafloor and that predicted by thermal models of the cooling of the oceanic lithosphere-the "missing heat" -indicates that fluid flow through the upper oceanic crust transports 8-11 TW globally (Hasterok, 2013; Stein and Stein, 1994). Fluid temperatures within the upper oceanic crust are typically $5-10^{\circ} \mathrm{C}$ higher than that of bottom water during the first 10-20 Myr after crustal accretion when most fluid-rock reaction occurs (Coogan and Gillis, 2018). At these temperatures, fluid fluxes of $\sim 0.6-1.7 \times 10^{16} \mathrm{~kg} \mathrm{yr}^{-1}$ (roughly $10-50 \%$ of the river flux) are required to transport the "missing heat". At modern seawater DIC levels of $\sim 2.3 \mathrm{mmol}$ $\mathrm{kg}^{-1}$, this equates to $\sim 1.5-4 \times 10^{13}$ moles of $\mathrm{C}$ passing through off-axis hydrothermal systems annually.

Fluid-rock reactions within the uppermost crust lead to dissolution of basaltic phases (e.g. glass, feldspar, pyroxene) and precipitation of secondary minerals such clays, zeolites and calcite (or aragonite), providing a sink for ocean DIC (carbon from the ocean-atmosphere system). Because finding and sampling fluids exiting off-axis hydrothermal systems is technically challenging, most observational constraints on the role of seafloor weathering in the long-term carbon cycle come from studies of rocks altered in such systems. Staudigel et al. (1989) presented the first detailed study of C-uptake during seafloor weathering focusing on three closely spaced drill cores from the western Atlantic showing that the lavas in these holes had taken up substantial seawater $\mathrm{C}$ in the lava section $\left(\sim 2.9 \mathrm{wt} \% \mathrm{CO}_{2}\right.$, equivalent to $\sim 2.9 \times 10^{12} \mathrm{~mol}^{-1}$ if these were globally representative). The only way to have such a large C-uptake by the crust ( $10 \%$ of the $C$ that passes through the crustal aquifer) appears to be through alkalinity generation during seafloor weathering reactions (Coogan and Gillis, 2013; Spivack and Staudigel, 1994). Francois and Walker (1992) proposed that this seafloor weathering $\mathrm{C}$-sink depended on bottom water $\mathrm{pH}$ and $\mathrm{DIC}$, and that it provided the dominant negative feedback on the long-term carbon cycle. However, at the near-neutral $\mathrm{pH}$ of seawater, the $\mathrm{pH}$ dependence of weathering rates is limited, leading Caldeira (1995) to suggest that this feedback mechanism was unlikely to be effective.

Nonetheless, observations from a larger number of ocean crust drill cores have now shown that the total $\mathrm{CO}_{2}$ uptake by the lava section of the oceanic crust through time is variable and was significantly higher for crust formed in the late Mesozoic than late Cenozoic (Alt and Teagle, 1999; Gillis and Coogan, 2011). Further, most upper oceanic crust carbonate is precipitated within the first 20 Myr after crustal accretion (Coogan and Dosso, 2015; Coogan et al., 2016; Staudigel and Hart, 1985), suggesting that this difference in $\mathrm{CO}_{2}$ content reflects something intrinsically different about the system between these times-the most likely candidates being differences in ocean temperature and composition. A significant temperature dependence experiments and is supported by modeling Sr-isotope systematics in these systems (Coogan and Dosso, 
2015) and by global C-cycle models (Krissansen-Totton and Catling, 2017). Additionally, O-isotope

561 thermometry shows that both the minimum and average temperature of precipitation of carbonate in the upper oceanic crust track bottom water temperature, being higher in the late Mesozoic than late Cenozoic (Coogan and Gillis, 2018; Gillis and Coogan, 2011). These observations lead to a simple model for the role of seafloor weathering of basalts in the long-term carbon cycle in which increased atmospheric $\mathrm{CO}_{2}$ gives rise to an increased global mean surface temperatures, and in turn increase in bottom water temperature of the same magnitude (Krissansen-Totton and Catling, 2017). Thus, the temperature of seawater-basalt reactions in the upper oceanic crust increases leading to elevated $\mathrm{CO}_{2}$ consumption (alkalinity generation) and a stabilizing feedback on the C-cycle.

\subsection{Internal Carbon Recycling (Reverse Weathering)}

To our knowledge, the notion of reverse weathering (and marine weathering) can be traced back to a seminal paper by Sillén (1961), where clay minerals are proposed to act as a buffer of seawater $\mathrm{pH}$. In this contribution and subsequent publications, Sillén questioned the traditional view of a carbonate system operating as the sole regulator of seawater $\mathrm{pH}$, highlighting that significant amounts of seawater alkalinity could be released (marine weathering) and/or consumed (reverse weathering) by silicate mineral phases (Sillén, 1961, 1967). Multiple articles followed within the decade, predominantly focused on highlighting the importance of reverse weathering for the budgets of multiple major cations, alkalinity and $\mathrm{H}^{+}$(Garrels, 1965; Holland, 1965; Mackenzie and Garrels, 1965, 1966a, b). Perhaps most notably, Mackenzie and Garrels constructed a mass balance for river water inputs, such that the major constituents were precipitated from seawater as mineral phases commonly found in marine sediments-balancing their budgets required for $\mathrm{Na}$, $\mathrm{Mg}, \mathrm{K}$ and Si removal through clay authigenesis (Mackenzie and Garrels, 1966a, b).

Subsequently, both field (e.g., Baldermann et al., 2015; Baldermann et al., 2013; Ehlert et al., 2016; Ku and Walter, 2003; Mackenzie et al., 1981; Mackin and Aller, 1984, 1986; März et al., 2015; Michalopoulos and Aller, 1995, 2004; Michalopoulos et al., 2000; Presti and Michalopoulos, 2008; Rahman et al., 2016, 2017; Ristvet, 1978; Solomon et al., 2008; Tatzel et al., 2015; Wallmann et al., 2008) and laboratory studies (Loucaides et al., 2010; Michalopoulos and Aller, 1995) investigating the mineralogy and pore-water chemistry of modern marine sediments and their evolution with depth have provided convincing evidence for the operation of this process in the natural environment, prompting greater acceptance within the broader community. Most recently, studies of both stable Si (Ehlert et al., 2016) and cosmogenic Si (Rahman et al., 2016, 2017) isotopes have been developed as a tracer for fingerprinting Si uptake during authigenic clay formation in marine sediments. Similar to marine weathering, reverse weathering has been observed to take place in both marine sediments (e.g., Ehlert et al., 2016) and oceanic crust (e.g., Chan et al., 1992; Chan et al., 2002; Chan and Kastner, 2000). Note that the latter should not be confused with cation exchange between fluids and primary mineral phases in oceanic crust (Berner and Berner, 2012), which have no direct effect on the global marine alkalinity balance.

On the basis that silica forms the framework of all clay minerals, the global silica cycle provides for a useful method of keeping track of reverse weathering fluxes. Largely based on extrapolations from work carried 
out in the proximal Amazon delta (Michalopoulos and Aller, 2004), dissolved silica sequestration as 601 authigenic clay phases globally was initially estimated at 1 to $1.5 \mathrm{Tmol} \mathrm{yr}^{-1}$ (Holland, 2005; Laruelle et al., 2009; Tréguer and De La Rocha, 2013). For reference, the total amount of new Si introduced into the ocean

603 system is estimated at $\sim 10.9 \mathrm{Tmol} \mathrm{yr}^{-1}$ (Tréguer and De La Rocha, 2013). However, most recent work 604 adopting the use of cosmogenic ${ }^{32} \mathrm{Si}$ suggest that this flux could be significantly higher at $\sim 4.5$ to $4.9 \mathrm{Tmol}^{-1} \mathrm{r}^{-1}$ 605 globally in coastal and deltaic systems (Rahman et al., 2017). In this novel contribution, ${ }^{32} \mathrm{Si}$ is applied as a tracer for studying Si release during biogenic silica dissolution and its re-capture by authigenic phases in marine sedimentary porewaters (Rahman et al., 2017). The capture of cosmogenic ${ }^{32} \mathrm{Si}$ (generated by cosmic ray spallation of ${ }^{40} \mathrm{Ar}$ in the atmosphere) by biogenic silica (e.g., diatoms) upon entering the ocean, delivers the ${ }^{32} \mathrm{Si}$ to the sediment-water interface after the organism dies. As such, these estimates do not account for (1) shelf, slope, upwelling and deep sea environments, and (2) any amount of Si capture that was derived from direct diffusion with marine bottom waters and/or Si released via dissolution of primary silicate minerals (marine weathering) that do not host ${ }^{32} \mathrm{Si}$, and, therefore, can be viewed as conservative.

Reverse weathering can involve a variety of different dissolved cation species (e.g., $\mathrm{Li}^{+}, \mathrm{K}^{+}, \mathrm{Mg}^{2+}, \mathrm{Fe}^{2+}$ ), and so keeping track of this process through any of these individual cycles will provide an incomplete view of its impact on the global carbon and alkalinity budgets. Similarly, the global export of Si does not translate directly to a flux of carbon being recycled through reverse weathering. However, with knowledge of the alkalinity (Alk) : silica ( $\mathrm{Si}$ ) consumption ratio associated with clay authigenesis, that is determined by the composition (clay species) of the globally integrated clay mineral assemblage, the reverse weathering flux of $\mathrm{CO}_{2}$ can be estimated. A clay mineral species/assemblage with a higher Alk:Si ratio will have a larger impact on global carbon recycling (e.g., Isson and Planavsky, 2018). The formation of kaolinite, for instance, does not consume soluble cations and thus alkalinity, and so has no impact on the global carbon cycle. Alk:Si ratios of standard clay compositions (note that many have flexible stoichiometries) span a large range between kaolinite and up to 4.0. For instance, sepiolite has an Alk:Si= 1.33, greenalite $=3.0$, berthierine $=$ 4.0. The activities of dissolved cations, silica, $\mathrm{H}^{+}$and temperature all play a role in regulating the saturation state and thus rate of formation of an authigenic clay mineral phase. The dependence $(A, B, C)$ of each one is set by the stoichiometry of the clay mineral (for instance if $\mathrm{X}_{A} \mathrm{Si}_{B} \mathrm{O}_{5}(\mathrm{OH})_{4}$, and $\mathrm{C}=\mathrm{A}$ for a monovalent cation and $\mathrm{C}=\mathrm{A} \times 2$ for a divalent cation)

$$
\mathrm{K}_{\mathrm{sp}}=\frac{\alpha_{\text {cation }}^{A}+\alpha_{\text {SiO2(aq) }}^{B}}{\alpha_{H^{+}}^{C}}
$$

Organic matter remineralization reactions have the potential to alter marine porewater chemistry and $\mathrm{pH}$ levels and their evolution with depth in the sediment pile, that have the potential to influence rates of reverse weathering (and forward marine weathering). Hydrogen ion and alkalinity budgets evolve with depth in marine sediments. Specifically, the oxidation of organic matter tied to aerobic respiration and methanogenesis generates acidity while iron and sulfate reduction consumes acidity. Thus all else being equal, the chemistry of the upper portion of an anoxic marine sediment pile above the sulfate-methane transition zone would be expected to produce conditions that favor reverse weathering type reactions (increase saturation state of silicate minerals), and favor marine weathering below it (Section 3.2.5). 


\section{Evolution of the Global Carbon Cycle}

\subsection{Controls on Degassing and its Evolution}

All of the major carbon dioxide outgassing sources can potentially vary dramatically through time. There are likely unidirectional changes in the history of outgassing, tied to Earth's long-term thermal and tectonic evolution and, superimposed on this shorter-term cyclic changes on the order of several million years linked to tectonic processes. Historically, a long-term drop in mantle heat flow is assumed to drive a progressive decline in mid ocean ridge spreading rates and thus ridge $\mathrm{CO}_{2}$ fluxes. But this rapid spreading rate model clashes strongly with empirical observations and first principle geophysical modeling, which provide strong evidence that the early Earth was instead characterized by slow rates of ocean ridge spreading (Korenaga, 2018). This, however, does not imply that there has been no decline in outgassing rates through Earth's history. Most importantly, there is compelling evidence from modeling the ${ }^{142} \mathrm{Nd}$ isotope and zircon records that crustal recycling rates have declined through Earth's history-with the most precipitous decline in the Archean (Korenaga, 2018; Rosas and Korenaga, 2018). These enhanced rates of continental crustal recycling would have driven enhanced $\mathrm{CO}_{2}$ outgassing in the Precambrian, providing part of the solution to the faint young Sun paradox. Rates of outgassing are also likely to have varied during 'supercontinent' cycles which occur on a roughly 150 Myr time scale, and during magmatic flare ups which often occur on a several million year time scale, but can also occur over much shorter intervals (e.g., Burgess et al., 2014).

There is no debate that outgassing fluxes likely varied through Earth history, but it is difficult to provide constraints on outgassing evolution. This is not surprising, given that there are large uncertainties even in modern outgassing fluxes (see section 3.1). An exception to this rule is continental arc systems, which have the potential to contribute large fluxes of $\mathrm{CO}_{2}$ to the atmosphere due to recycling of carbon preserved in the upper plate (Lee and Lackey, 2015; Lee et al., 2013; Mason et al., 2017). Detrital zircon U-Pb ages extracted from clastic sedimentary rocks provide a means to assess regional continental magmatism in deep geologic time. Zircon is an accessory mineral commonly produced in silicic magmas (e.g., Lee and Bachmann, 2014), which are produced in large volumes along continental arc systems. Mafic rocks can certainly contain zircons; however, they are far less abundant than in the higher silicic content rocks. Zircons can remain in upper crustal rocks for extended intervals of time because of the mineral's resilience to physical and chemical degradation (e.g., Gehrels, 2014). Thus, zircon can survive multiple episodes of sedimentary recycling (i.e., burial, exhumation, erosion and reburial). This is why a sandstone may contain a wide variety of zircons with crystallization ages billions of years older than the depositional age of the rock-even modern river sands can yield Archean aged zircon (Campbell and Allen, 2008). Clastic sediments deposited along continental margins with arc systems, however, tend to contain large abundances of zircon with crystallization ages close to the depositional age of the sediment (Cawood et al., 2012), which are likely firstcycle zircons sourced from volcanic or rapidly exhumed plutonic rocks produced by the arc system. Sediment collected in close proximity to the arc will generally be dominated by relatively young arc-derived zircons, whereas zircon collected further away from the arc will likely contain mixed zircons from older bedrock sources and with the abundance of the young grains being reduced (Blum and Pecha, 2014; Capaldi et al., 2017). 
The marine environment has changed dramatically with the advent of a deep sea carbon burial in the Mesozoic (Ridgwell, 2005), and this shift in the carbonate factory could have changed $\mathrm{CO}_{2}$ outgassing. Specifically, this would increase the chances that a subducting slab was rich in carbonates, which (in the standard view) should increase the amount of carbonate recycled and degassed as $\mathrm{CO}_{2}$ in arc systems (e.g., Edmond and Huh, 2003). Interestingly, however, there is no evidence for a step increase in surface temperatures associated with the emergence of deep-sea carbon burial; although the Cretaceous is an anomalously warm period, the Cenozoic is an anomalously cool period. There is increasing evidence for $\mathrm{CO}_{2}$ degassing from metacarbonate rock in the overriding plate when there is fluid infiltration (Stewart and Ague, 2018). In this case, the arc systems before and after the onset of extensive deep sea carbon burial may have, on average, had roughly similar ratios of $\mathrm{CO}_{2}$ outgassed to new zircons produced. Regardless, of this uncertainty, it is reasonable to assume that careful assessment of detrital zircon age-data may provide first order insights into global continental magmatism and $\mathrm{CO}_{2}$ outgassing through time.

Recent studies have utilized global detrital zircon U-Pb data to track the spatial distribution of arc systems at various time scales (McKenzie et al., 2016; McKenzie et al., 2014). A general problem in studies utilizing zircon age compilations is the unevenness of data available, which biases composite global age distributions from being truly "global"-most distributions are biased towards regions which contribute a substantial amount of data (Campbell and Allen, 2008; Voice et al., 2011). McKenzie et al. (2016) attempted to circumvent these sampling issues by binning their data by geographic region and depositional age, which allowed the regional data to be normalized prior to incorporation into temporal composites. There are likely more sophisticated ways to avoid sampling biases, and as databases increase there will certainly need to be future assessment of these records. But at present, this simple normalization process provides a reasonable means of assessing how global zircon production has changed throughout time.

The sedimentary record of zircon production was assessed in sediments ranging from the Cryogenian to the present (i.e., the past 720 million years of Earth history) and demonstrated a correlation with icehousegreenhouse transitions. This suggests a causative link between arc activity and climate transitions-when volcanism was reduced Earth moved into an icehouse state, whereas when volcanic arcs expanded, Earth moved into a greenhouse climate (McKenzie et al., 2016). Correlation-even when there is an obvious mechanistic link-does not, of course imply causation. Any future work attempting to tease apart the effects of production versus preservation on the sedimentary zircon record and test the proposal that this record can faithfully track arc activity would be of great interest to the community. However, the current sedimentary zircon record points towards carbon outgassing history playing a critical role in shaping Earth's

\section{2 climate.}

713

714 Conclusions about outgassing from the zircon record can be tested to a degree by (1) considering how 715 continents have migrated and amalgamated throughout time (i.e., supercontinent break-up and formation); 716 and/or (2) mapping the known distribution of ancient volcanic systems. Continental break-up requires the 717 establishment of rift systems and the opening of new ocean basins, which also requires the establishment of 718 subduction zones to accommodate oceanic spreading. Therefore, as plates break up and migrate around, 
volcanic arc systems will be more prevalent, whereas the collision of continental blocks shuts down and reduces arc systems. Extensive continental arc systems existed throughout the Ediacaran and early Paleozoic to form Gondwana, during the mid-Paleozoic to form Pangea, and the Mesozoic to early Cenozoic following the breakup of Pangea. These intervals correspond with greenhouse climates, whereas the final collisions that formed Gondwana, Pangea, and the closure of the Tethys ocean (Cawood and Buchan, 2007; Lee et al., 2013) all correspond with icehouses (McKenzie et al., 2016; McKenzie et al., 2014). Mapping of arc systems in deep time is presently hindered by inconsistencies in reconstructing the extent and nature of magmatism along ancient margin configurations and problems with pre-Pangean plate configurations (e.g., Evans, 2013). Nonetheless, recent attempts to use paleogeographic maps to estimate arc length and outgassing have demonstrated similar results to that of the zircon record (Cao et al., 2017; Mills et al., 2017; Van Der Meer et al., 2014). Estimating the areal extent of regions undergoing low-, mid-, and high- grade metamorphic alteration, which can also be a major $\mathrm{CO}_{2}$ source (e.g., Stewart and Ague, 2018; Stewart et al., 2019; Zhang et al., 2018), is similarly hindered by inconsistent geologic reconstructions. But collectively, multiple lines of data from recent studies are demonstrating a consistent relationship between outgassing estimates and major shifts in climate (Cao et al., 2017; McKenzie et al., 2016; McKenzie et al., 2014; Mills et al., 2017; Van Der Meer et al., 2014). Therefore, empirical records support the idea that carbon sources have played a major role in controlling Earth's climate and provide a simple explanation for why Earth has toggled between icehouse-greenhouse intervals. Large igneous provinces have been linked to short term climate shifts (foremost the end Permian mass extinction and temperature spike; Burgess and Bowring (2015)), but cannot be linked to longer-term climate swings and shifts given their limited active lifespan.

\subsection{Links Between the Oxygen, Iron, Sulfur, and Carbon Cycles}

The iron and sulfur cycles both have the potential to drive significant variations in atmospheric carbon dioxide levels. There are multiple burial channels for iron and sulfur-sulfur can be buried as pyrite or sulfate evaporites, and iron can be buried as Fe-clays, Fe-carbonates, pyrite, or oxides. At steady state, the cycling of these elements does not impact the global carbon cycle. On the other hand, shifts in the iron and sulfur weathering and burial terms can drive transient yet geologically meaningful shifts in $p \mathrm{CO}_{2}$ tied to longterm imbalances in the global marine alkalinity budget. This idea builds on the same principles introduced for silicate weathering and reverse weathering-numerous iron and sulfur reactions either produce acidity or alkalinity. Sulfide and ferrous iron oxidation produce acidity while ferric iron and sulfate reduction produce alkalinity-potentially altering the ocean-atmosphere carbonic acid system balance and thus the ocean's capacity to hold inorganic carbon.

There are numerous scenarios whereby changes in the iron and sulfur cycles could have driven a rise or decline in atmospheric carbon dioxide levels. However, there are two scenarios that have been the most thoroughly explored and are most likely to have impacted Earth's climate on a several million-year time scale (Bachan and Kump, 2015; Torres et al., 2014). An increase in pyrite weathering coupled to carbonate weathering can drive a jump in atmospheric carbon dioxide levels as long as the resulting sulfate accumulates in the ocean or is deposited as evaporite (Torres et al., 2014). In contrast, enhanced sulfide 
oxidation directly coupled to enhanced pyrite burial does not have a direct effect on the global carbon cycle. This transient, sulfur driven $\mathrm{CO}_{2}$ source likely played an important role in shaping Cenozoic climate, where there was a marked and progressive increase in marine sulfate concentrations (e.g., Wortmann and Paytan, 2012).

The progressive oxidation of iron in the upper continental crust can also result in a net release of carbon dioxide. Foremost, oxidation of continental crust rich in siderite and the deposition of sediments rich in ferric iron can result in a net $\mathrm{CO}_{2}$ release. Bachan and Kump (2015) proposed that this process was likely important during the Archean-Paleoproterozoic transition, which saw Earth's first notable rise in atmospheric oxygen levels. Although there is strong evidence that the crust contained abundant Fe carbonates in the Archean-there is also abundant evidence for the deposition of Fe silicates (e.g., Johnson et al., 2018; Rasmussen et al., 2017) and Fe oxides (e.g., Bekker et al., 2014). Further, the oceans appear to have remained anoxic through most of the Precambrian and potentially even in the early Phanerozoic. Therefore, atmospheric oxygenation may not lead to a jump in ferric/ferrous ratio of marine sediments. Better constraints on the evolution of sedimentary iron speciation are needed to further evaluate this problem.

\subsection{Reverse Weathering Through Time}

Reverse weathering could have evolved dramatically through time (Fig. 10). In particular, it was recently proposed that reverse weathering rates were likely elevated in early Precambrian oceans, directly linked to the higher dissolved $\mathrm{Si}, \mathrm{Fe}$ and $\mathrm{Mg}$ levels that are traditionally viewed to be characteristic features of this time period (Isson and Planavsky, 2018). In this view, enhanced carbon recycling during this time could have sustained a significantly elevated $\mathrm{pCO}_{2}$ baseline, providing a solution to the faint young Sun paradox that does not necessitate invoking a significant reduction to the weatherability of Earth's surface. The subsequent radiation of siliceous organisms (sponges, radiolarians, and most recently diatoms) through the Phanerozoic forced a drop in dissolved marine Si levels, and thus the extent of reverse weathering and baseline $\mathrm{pCO}_{2}$ levels. Marine authigenic clay mineral assemblages are likely to have evolved through time. While authigenic clays have long been recognized to make up a significant portion of the mineralogical and textural makeup of marine sediments (e.g., Hazen et al., 2013), a wide variety of species have been reported (for example, palygorskite, montmorillonite, glauconite, saponite, berthierine, greenalite, minnesotaite) (Baldermann et al., 2015; e.g., Bhattacharyya, 1983; Hazen et al., 2013; Johnson et al., 2018; Pletsch, 2001; Rasmussen et al., 2015; Rasmussen et al., 2013; Rasmussen et al., 2017). For instance, Fe-rich clays with higher Alk:Si consumption ratios (e.g., greenalite, berthierine, chamosite) appear to be more abundant in anoxic Precambrian marine sediments than observed in the modern oceans characterized by lower Alk:Si consumption ratios such as montmorillonite. The drop in atmospheric $\mathrm{pCO}_{2}$ levels since the Precambrian (Kasting, 1987) can, to a significant degree be explained by this evolution of clay mineral assemblage and Alk:Si. 


\section{Future Directions}

Although there have been major steps forward in our understanding of the global carbon cycle in the past decade, many advances have resulted in more questions than answers. We make a case that marine processes (marine weathering and reverse weathering) are likely more important controls on long-term climate than traditionally envisioned (e.g., in contrast to Berner, 2004). However, there is an obvious need for better constraints on the extent and evolution of these processes. In large part, this will center on improving our understanding of global cation mass balances. For the $\mathrm{Mg}$ cycle, this entails working towards a better constraint on the balance of clay to dolomite formation, and how the flux of $\mathrm{Mg}$ to the oceans has changed through time as the composition of the upper continental crust and weathering intensities have evolved. Mg isotopes provide a promising means to track these fluxes (e.g., Higgins and Schrag, 2015). Similarly, recent work has highlighted the need for better estimates on the extent of iron burial that consumes alkalinity (Baldermann et al., 2015; Bhattacharyya, 1983; Rasmussen et al., 2015; Tosca et al., 2016) and there are poor empirical constraints on how iron fluxes to the oceans have changed through time. There is a need for a better basic understanding of the fate of $\mathrm{Na}$ and $\mathrm{K}$ in the ocean, particularly constraints on the fraction of these elements that are lost in alkalinity consuming versus producing reactions (e.g., reverse weathering reactions verses seafloor weathering of feldspars). The Ca cycle, with a single output term, is typically considered to be the best constrained cation geochemical cycle. However, counter to the standard view, it has been suggested-and not yet refuted-that hydrothermal Ca fluxes dominate the $\mathrm{Ca}$ input to the oceans (Caro et al., 2010).

In sum, there are still major uncertainties in the sources and sinks of all major cations even in the modern oceans, and the evolution of cation budgets through Earth's history are even more poorly understood. A multifaceted approach-more well-grounded models, more experimental data, and better constraints from the rock record-is needed to move forward our understanding of evolution of cation budgets. However, an increase in the amount of kinetic data for marine reactions (e.g., clay formation) might lead to the most significant steps forward in the short term. The amount of kinetic data for conditions relevant to basalt alteration and marine porewaters is well short of that for terrestrial soils.

Better constraints on outgassing fluxes are also essential to move forward our understanding of the longterm carbon cycle. Although there have been several recent large-scale efforts (e.g., Trail by Fire project) to better constrain volcanic outgassing rates, several fluxes are still highly speculative. Foremost, the diffuse outgassing flux is poorly constrained (Kelemen and Manning, 2015). This should not be a surprise since diffuse fluxes are of course more difficult to constrain than point sources. Given the importance of fluid infiltration in determining $\mathrm{CO}_{2}$ fluxes (Stewart and Ague, 2018), more mechanistic models of fluid flow in subduction zones and metamorphic terranes are also potentially promising targets. a strong impetus to translate our understanding of Earth's carbon cycle into a general theory for carbon cycling on terrestrial planets. Moving toward a more generally accepted view of the factors that have 
understanding how terrestrial planets evolve. The 'habitable zone' for exoplanets-where liquid water can exist-is typically delineated by assuming the maximum greenhouse gas capacity of a planet (Kasting et al., 1993). Therefore, a well-grounded general theory of carbon cycling on terrestrial planets is essential to predict how likely a planet within the habitable zone will sustain the evolution and persistence of life. Further, coupling astronomical data with carbon cycle modeling may even help us pinpoint exoplanets most likely to harbor life (i.e., ideal target for exoplanet atmospheric characterization).

\section{Summary}

Earth has been a habitable planet for over 4 billion years because of the persistence of stabilizing feedbacks in the global carbon and silicon cycles. Terrestrial silicate weathering was traditionally assumed to give rise to this negative feedback. Indeed, work over the last few decades suggests the presence of a terrestrial silicate weathering feedback (e.g., Von Strandmann et al., 2013). However, there are major uncertainties in the processes controlling terrestrial silicate weathering rates and in the balance between terrestrial and marine silicate weathering. The extent of silicate weathering in groundwater has likely been underappreciated. Similarly, marine weathering-both within the sediment pile and during oceanic crust alteration-is also likely a more important part of the global carbon cycle than was traditionally envisioned (Coogan and Gillis, 2018; e.g., Gillis and Coogan, 2011; Wallmann et al., 2008). In other words, terrestrial silicate weathering in the critical zone only accounts for part of the carbon removal from the oceanatmosphere system and global silicate weathering fluxes are much higher than those reconstructed from riverine alkalinity budgets. New evidence for higher modern weathering rates than traditionally envisioned does not imply that the carbon cycle is dramatically out of steady state; carbon source terms have likely also been underestimated. Foremost, carbon dioxide fluxes from diffuse metamorphic outgassing are almost certainly higher than in traditional balanced long-term carbon cycles budgets (e.g., Berner, 2004).

Authigenic clay formation in the oceans-reverse weathering-is a relatively minor part of the modern global carbon cycle, but it is likely to have been more important earlier in Earth's history (Isson and Planavsky, 2018). The switch to a biologically controlled Si cycle-where the majority of $\mathrm{SiO}_{2}$ fluxes in the oceans are biogenic-caused a dramatic drop in dissolved marine Si concentrations (Siever, 1992). This drop in dissolved marine Si concentrations would have decreased the saturation state of clay minerals-leading to less reverse weathering and more marine weathering. Reverse weathering, the rates of which are $\mathrm{pH}$ dependent, also stabilizes the climate system. Therefore, a biotic innovation ( $\mathrm{Si}$ biomineralization) destabilized the climate system, adding to one of the central dogmas of the original Gaia hypothesis, that life as a part of a global Earth system can give rise to both positive and negative climate feedbacks (Lovelock and Kump, 1994; Lovelock and Margulis, 1974).

Given that there is still debate about the modern carbon cycle mass balance, it is unsurprising that there is not a clear consensus about the factors that have driven long term shifts in Earth's climate. This debate is often distilled down into arguments about whether the sources or sinks of carbon sources have driven climate shifts. There is a strong correlation between outgassing tracers and climate records over the last 800 
878 million years (e.g., McKenzie et al., 2016; Mills et al., 2017), tentatively suggesting that carbon sources were 879 the main drivers of climate oscillations. However, shifts in weatherability (carbon sinks) have also been 880 linked to major climate shifts (e.g., Cenozoic cooling; Caves et al., 2016; Jagoutz et al., 2016; Zhang and 881 Planavsky, 2019). Resolving the factors controlling climate shifts and working towards a more well-defined 882 global carbon mass balance are obvious areas of future research.

\section{Acknowledgements}

884

885 EWB acknowledges support from the Virtual Planetary Laboratory NASA NAI. NJP and TTI acknowledges 886 support from the Alternative Earths NASA NAI. LRK is supported by the Heising Simons Foundation. JJA and 887 EMS acknowledge support from the National Science Foundation (EAR-1650329). The authors acknowledge 888 discussions with G.E. Bebout, R.A. Berner, O. Beyssac, A.V. Brovarone, C.P. Chamberlain, T. Lyons, B. Marty, 889 F. Piccoli, D. Rumble, C. Reinhard, M. Scambelluri, C.M. Schiffries, D.M. Rye, and also comments from Cin-Ty 890 A. Lee and one other anonymous reviewer. 
Table 1.

\begin{tabular}{ll}
\hline Carbon Reservoirs & Mass $\left(10^{18} \mathrm{~mol}\right)$ \\
\hline & 2.8 \\
Ocean & 0.06 \\
Atmosphere & 0.3 \\
Soil & 0.06 \\
Terrestrial Biosphere & 0.05 \\
Marine Biosphere & 6250 \\
Upper Continental Crust \\
$\quad$ (Carbonate C in rocks) \\
$\quad$ (Organic C in rocks)
\end{tabular}

* Source Berner 2004 
Table 2. Modern Global Carbon Cycle Budget.

\begin{tabular}{|c|c|c|}
\hline Source / Sink & $\begin{array}{l}\text { Flux } \\
\left(10^{12} \mathrm{~mol} \mathrm{yr}^{-1}\right)\end{array}$ & Ref. \\
\hline \multicolumn{3}{|l|}{$\mathrm{CO}_{2}$ Sources } \\
\hline Collisional Metamorphism & $0.5-7.0$ & (Becker et al., 2008; Stewart and Ague, 2018) \\
\hline Subduction Metamorphism (Diffuse) & $0.3->>1.0$ & (Kelemen and Manning, 2015) \\
\hline Arc Volcanism & $1.5-3.5$ & $\begin{array}{l}\text { (Dasgupta and Hirschmann, 2010; Hilton et al., 2002; Marty and } \\
\text { Tolstikhin, 1998) }\end{array}$ \\
\hline Mid Ocean Ridge & $1.0-5.0$ & $\begin{array}{l}\text { (Chavrit et al., 2014; Dasgupta and Hirschmann, 2006, 2010; } \\
\text { Hirschmann, 2018; Marty and Tolstikhin, 1998; Matthews et al., 2017; } \\
\text { Saal et al., 2002) }\end{array}$ \\
\hline Ocean Island & $0.12-3.0$ & (Dasgupta and Hirschmann, 2010; Marty and Tolstikhin, 1998) \\
\hline Reverse Weathering (Alk:Si = 1-2) & $0.5-10.0$ & (Rahman et al., 2016; Tréguer and De La Rocha, 2013) \\
\hline \multicolumn{3}{|l|}{$\mathrm{HCO}_{3}-$ Sources } \\
\hline $\begin{array}{l}\text { Terrestrial Weathering } \\
\text { (not including groundwater) }\end{array}$ & $11.5-23$ & (Gaillardet et al., 1999; Li and Elderfield, 2013) \\
\hline Oceanic Crust Weathering & $0.2-3.75$ & (Coogan and Gillis, 2018) \\
\hline Marine Sediment Weathering & $5-20$ & (Wallmann and Aloisi, 2012; Wallmann et al., 2008) \\
\hline \multicolumn{3}{|l|}{$\mathrm{HCO}_{3}^{-}$Sinks } \\
\hline Biogenic Carbonate & $14-25$ & (Wallmann and Aloisi, 2012) \\
\hline Authigenic Carbonate (Sediment) & $0.5-1.5$ & (Sun and Turchyn, 2014) \\
\hline Authigenic Carbonate (Oceanic Crust) & $1.5-2.4$ & (Coogan and Gillis, 2018) \\
\hline
\end{tabular}




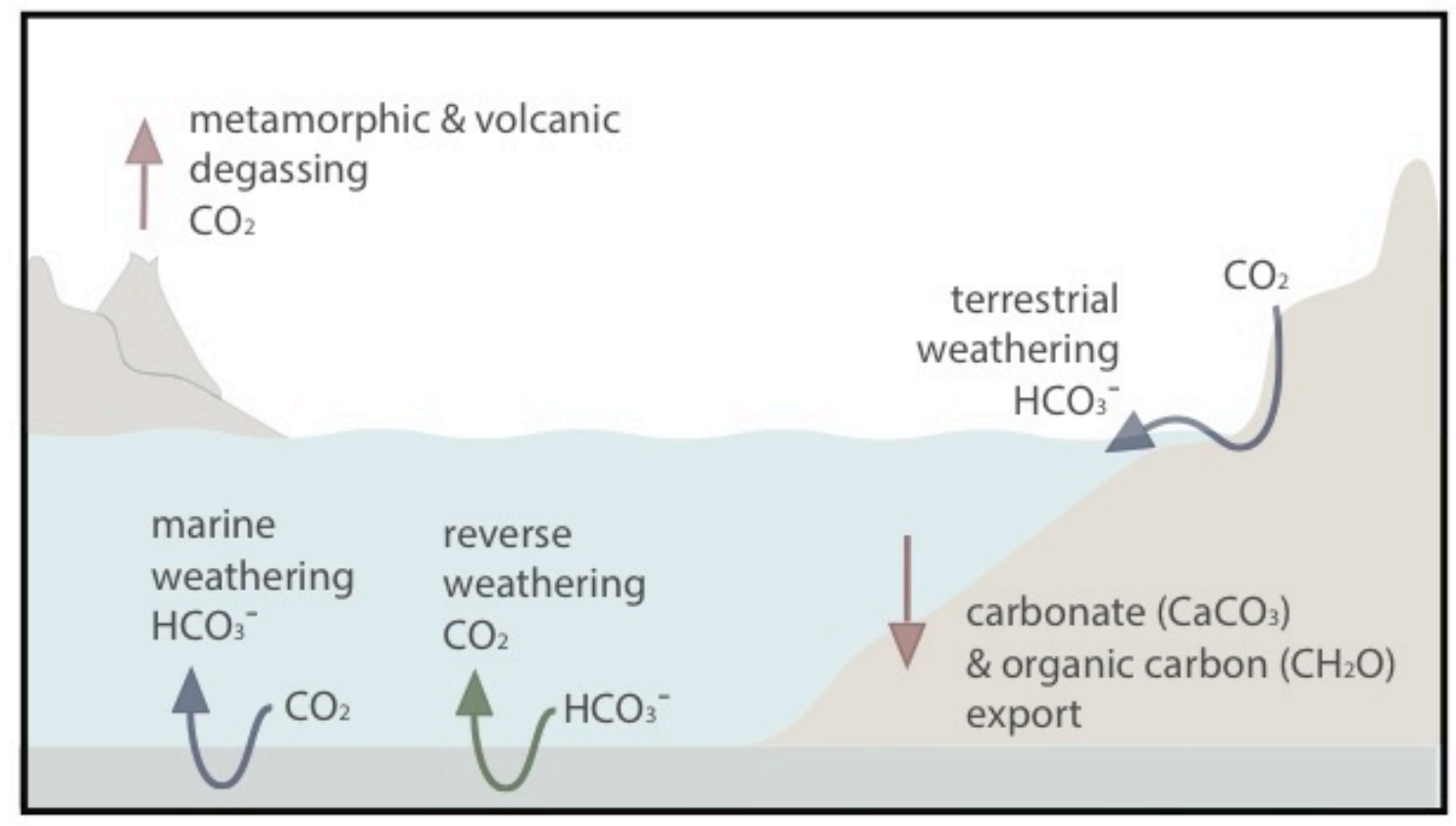

Fig. 1. Simplified cartoon illustrating the inorganic portion of the global long-term carbon cycle.

Red arrows indicate carbon entering and leaving the ocean-atmosphere system. Blue and green arrows indicate weathering and reverse weathering processes that alter the species of carbon (between $\mathrm{CO}_{2}$ and carbonate alkalinity) within the ocean-atmosphere system. 
a)

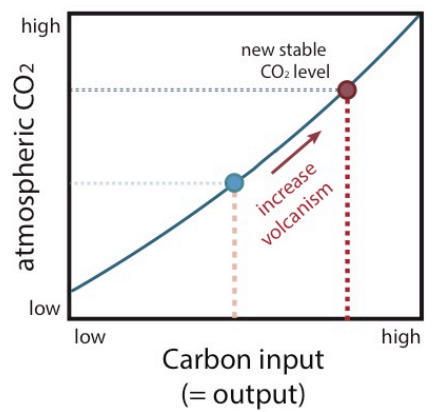

d) Weatherability

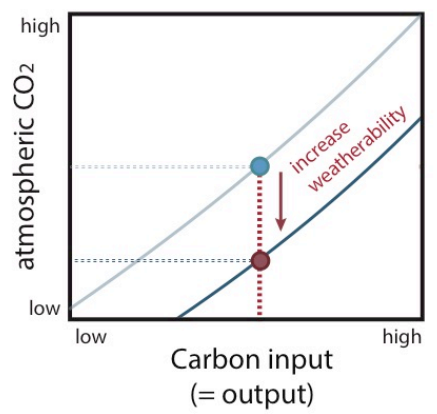

b) Silicate Weathering

Feedback Strength

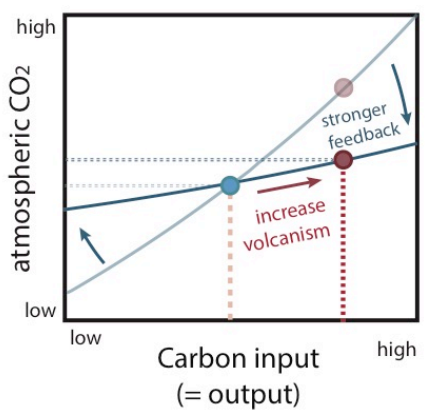

e) Reverse Weathering

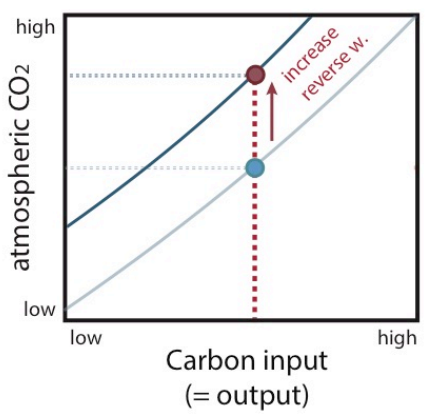

c) Organic Carbon or Carbonate Preservation

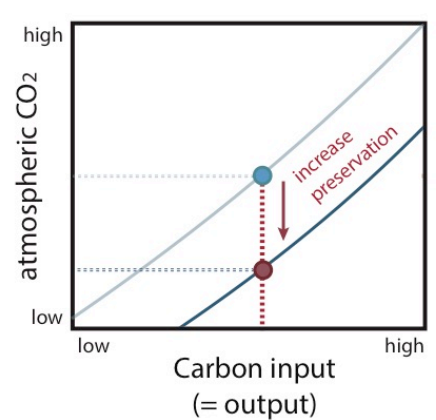

f) Marine Weathering (M.W.) : Terrestrial Weathering (T.W.)

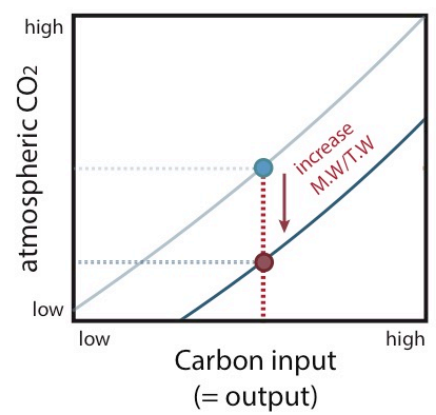

Fig. 2. Key principles of the global carbon cycle and atmospheric $\mathrm{CO}_{2}$.

The effect of (a) outgassing, (b) strength of the silicate weathering feedback, (c) organic carbon and carbonate sequestration, (d) weatherability, (e) reverse weathering and (f) ratio of marine to terrestrial weathering on long-term stable state atmospheric $\mathrm{pCO}_{2}$ levels. Carbon input is the total new carbon flux added into the ocean-atmosphere system, and output is the total carbon flux removed from the system (which equals input at steady state). 
a)

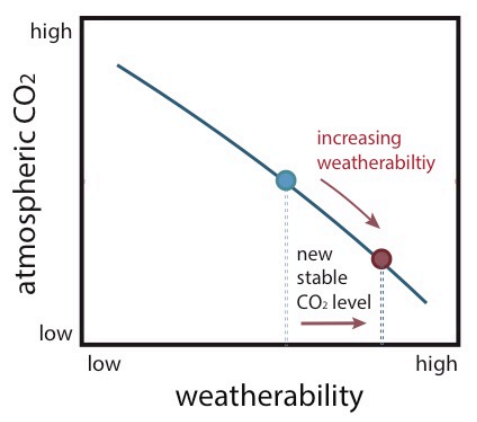

c)

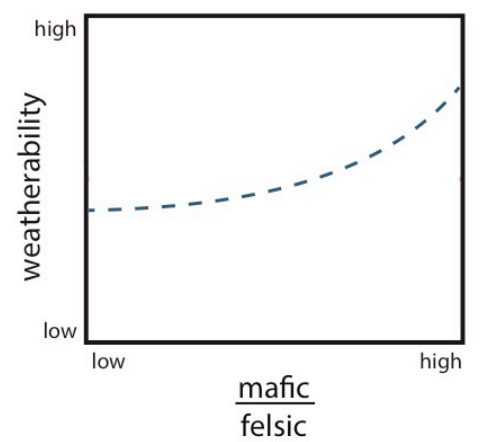

b)
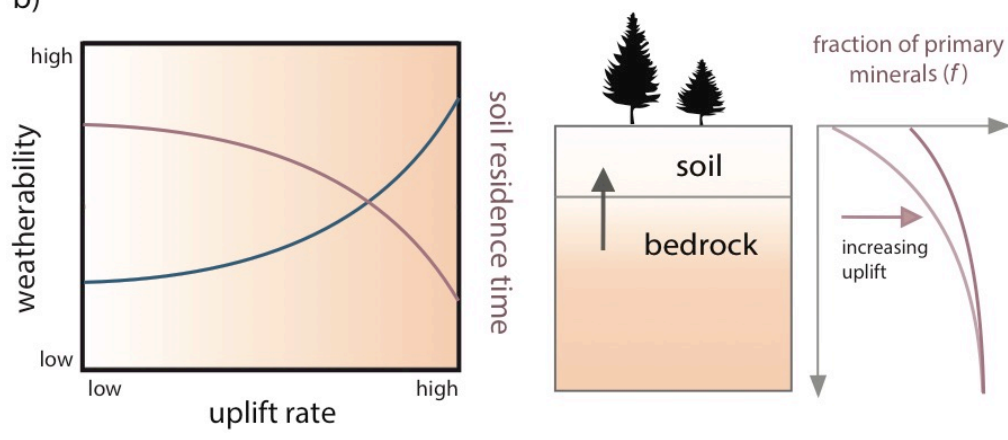

Fig. 3. Controls on weatherability.

For a set carbon input, any increase in weatherability would lead to a drop in stable state $\mathrm{pCO}_{2}$ levels (panel a). Factors that have been proposed to regulate weatherability include uplift rates (panel b), the composition of the weatherable crust (panel c), and the degree of biological alteration (panel d). Higher uplift rates and increasing the fraction of exposed of basalts (shifting mafic/felsic ratio) act to increase weatherability. Higher uplift rates lead to a higher proportion of fresh weatherable primary mineral phases (and a shorter soil residence time) within the weathering horizon at Earth's surface (e.g., Lee et al., 2015; Maher and Chamberlain, 2014). In panel b, more intense colors indicate a higher fraction of weatherable minerals within the weathering horizon. Note that the effects of uplift are more well established than increasing basalt area. 


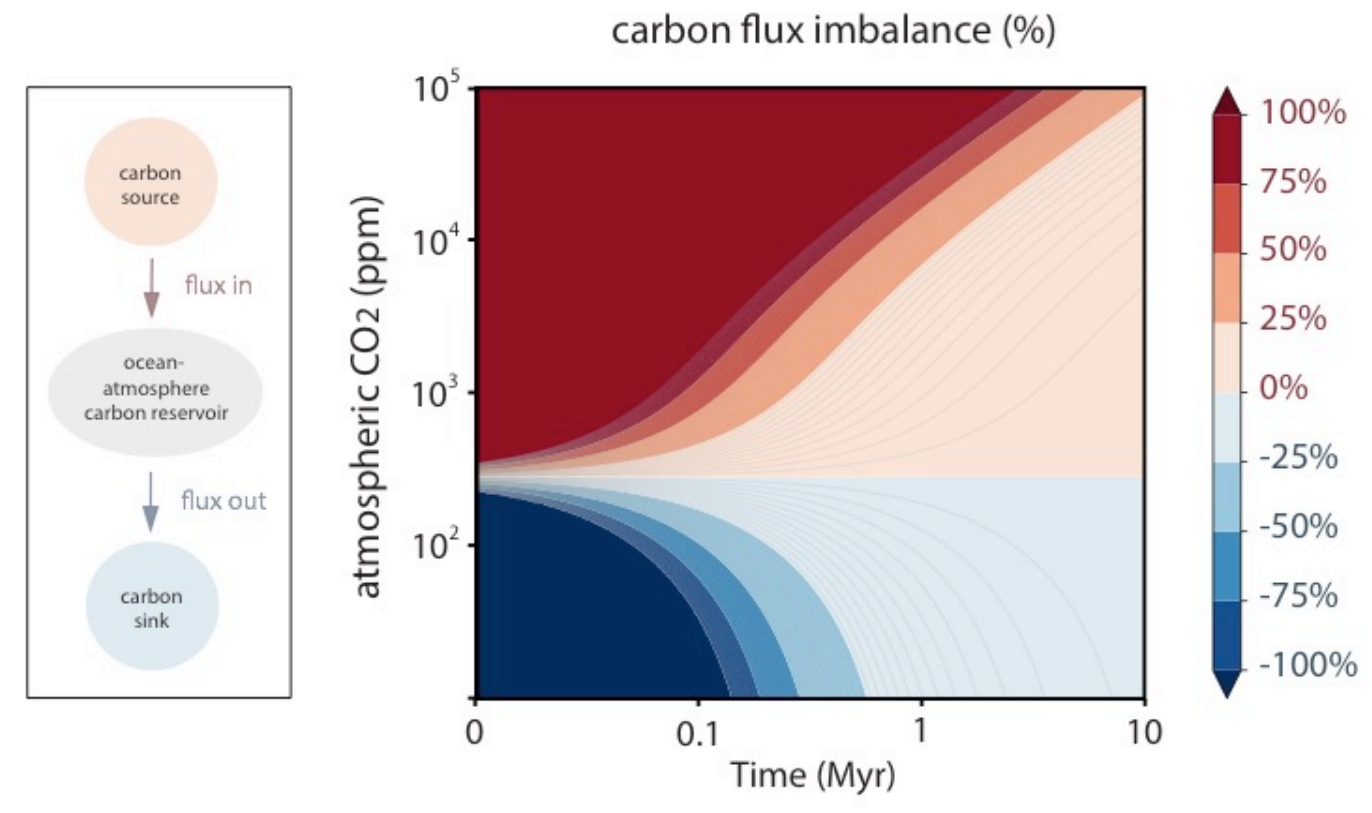

Fig. 4. Global carbon cycle box model demonstrating that carbon input must equal output (steady-state) on geologic time scales (adapted from Berner and Caldeira, 1997).

In the absence of a stabilizing feedback, sustained imbalances (excess input or output) will very rapidly lead to either runaway icehouse or greenhouse conditions. Color bar indicates \% imbalance between input and output of carbon from the ocean-atmosphere system. Blue indicates excess output and red excess input. 


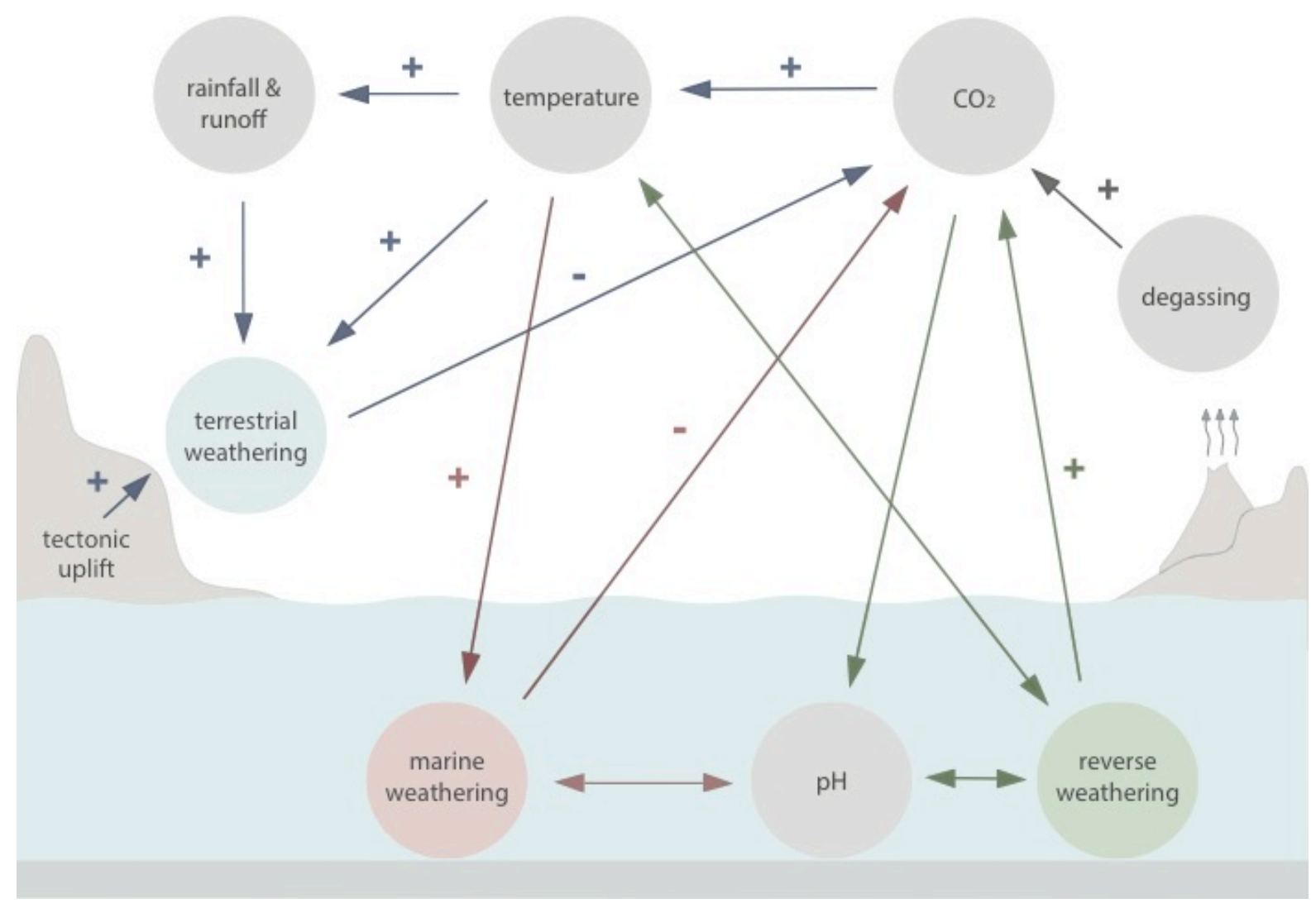

Fig. 5. Schematic of the processes that give rise to Earth's thermostat.

Three main stabilizing feedbacks associated with the global carbon cycle: $(A)$ terrestrial silicate weathering (blue); (B) marine silicate weathering (red); (C) reverse weathering (green). 


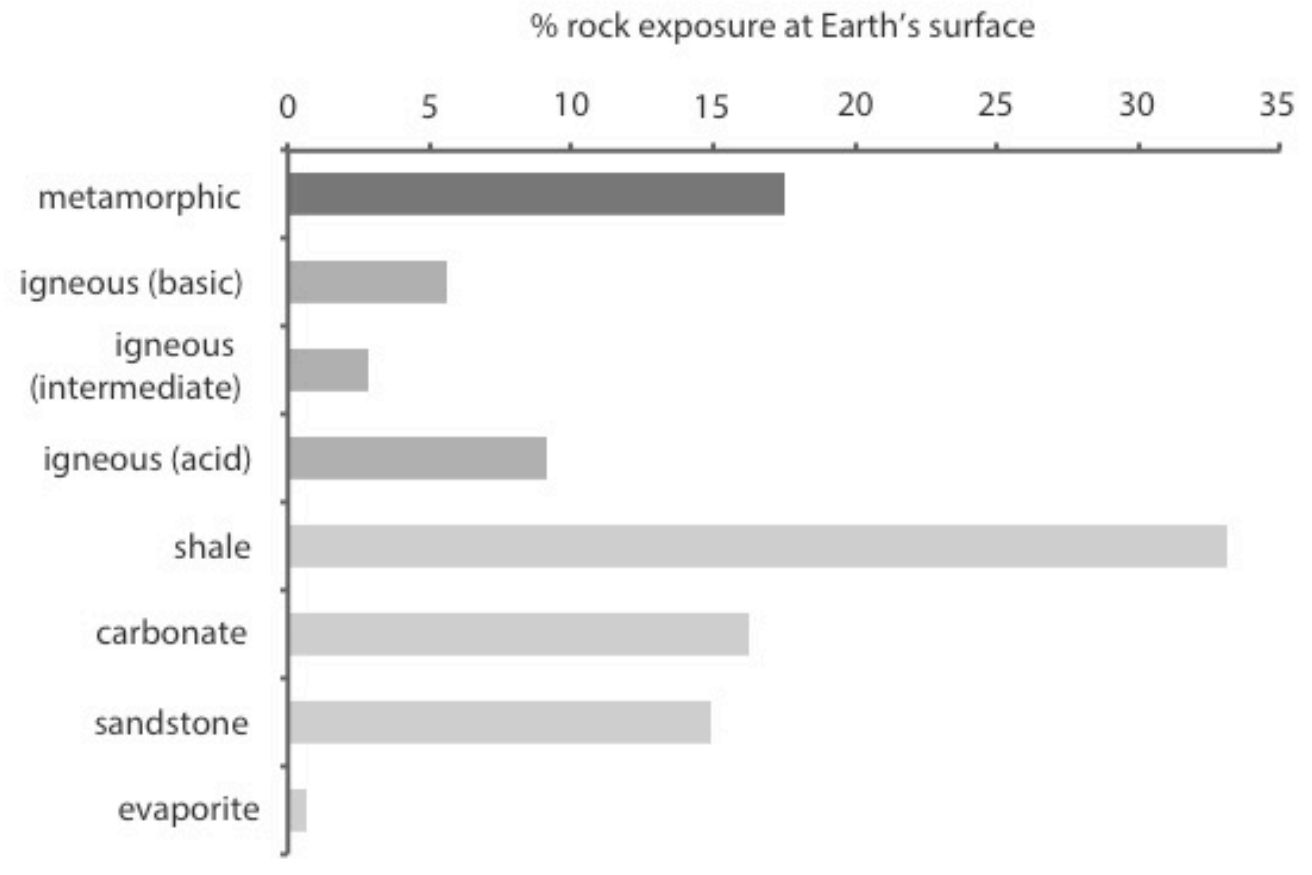

Fig. 6. Composition of the modern upper continental crust (Suchet et al., 2003)

Rock exposure at Earth's surface is dominated by sedimentary rock. This includes the metamorphic component, which is estimated to consist of $\sim 90 \%$ metasedimentary rock. 


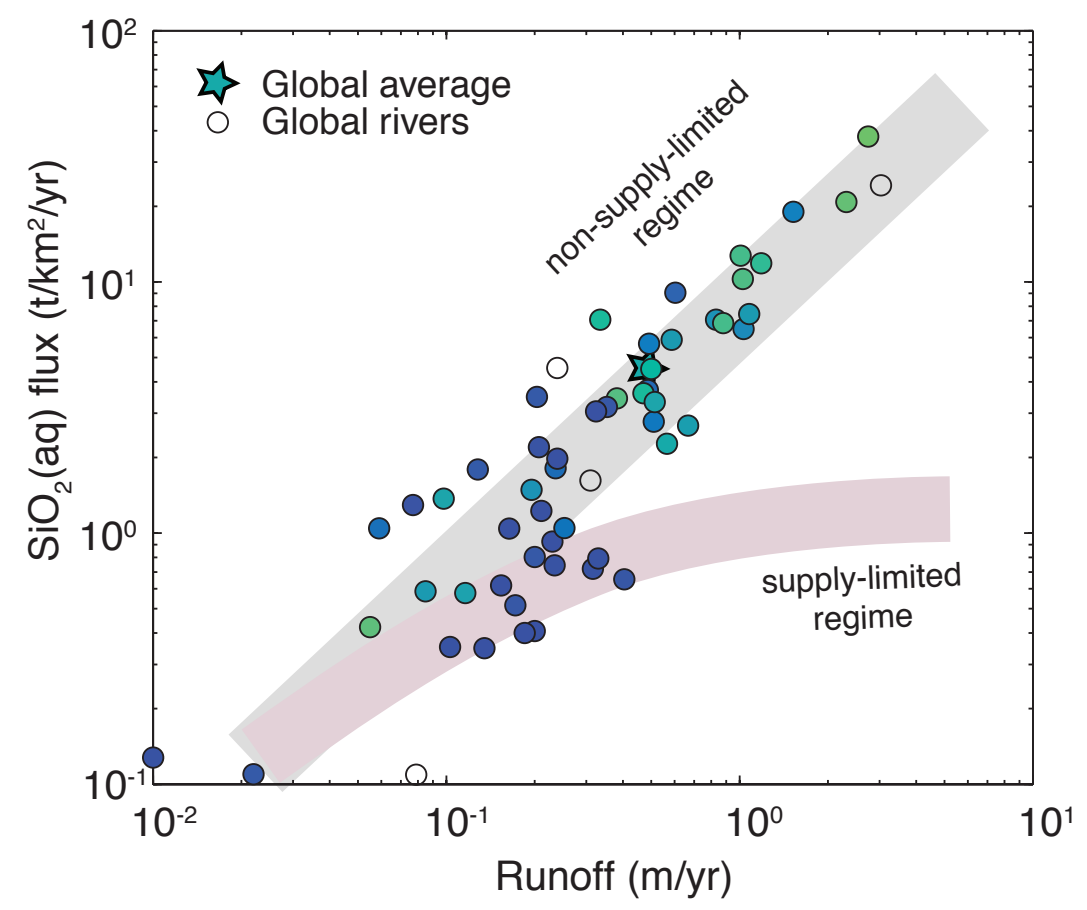

Fig. 7. Global geochemical river datasets indicate that Earth's system as a whole is not supply-limited.

In a supply limited Earth system, an increase in rainfall (more intense hydrology) will not be met by an increase in chemical weathering rates. Earth's river system however, indicates a strong correlation between the acceleration of the hydrological cycle and chemical weathering rates (data from Maher and Chamberlain, 2014). 

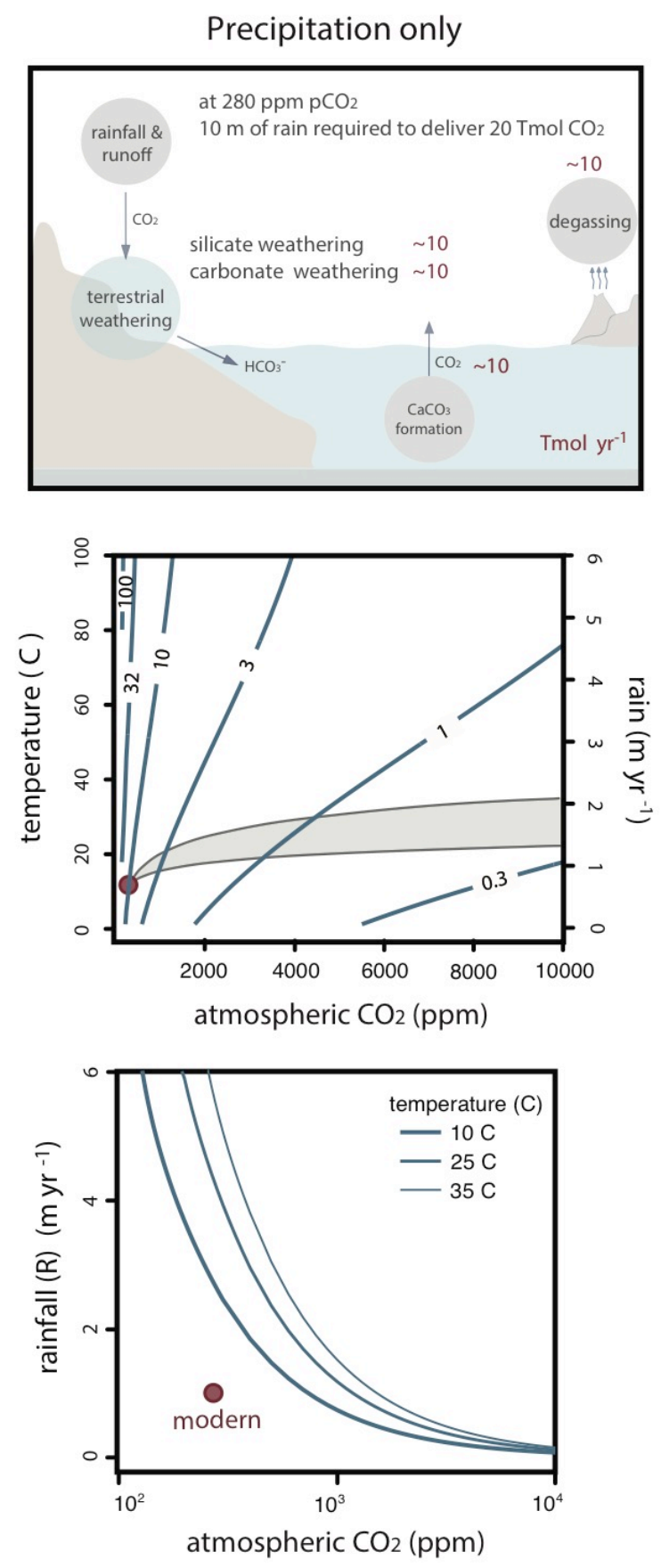
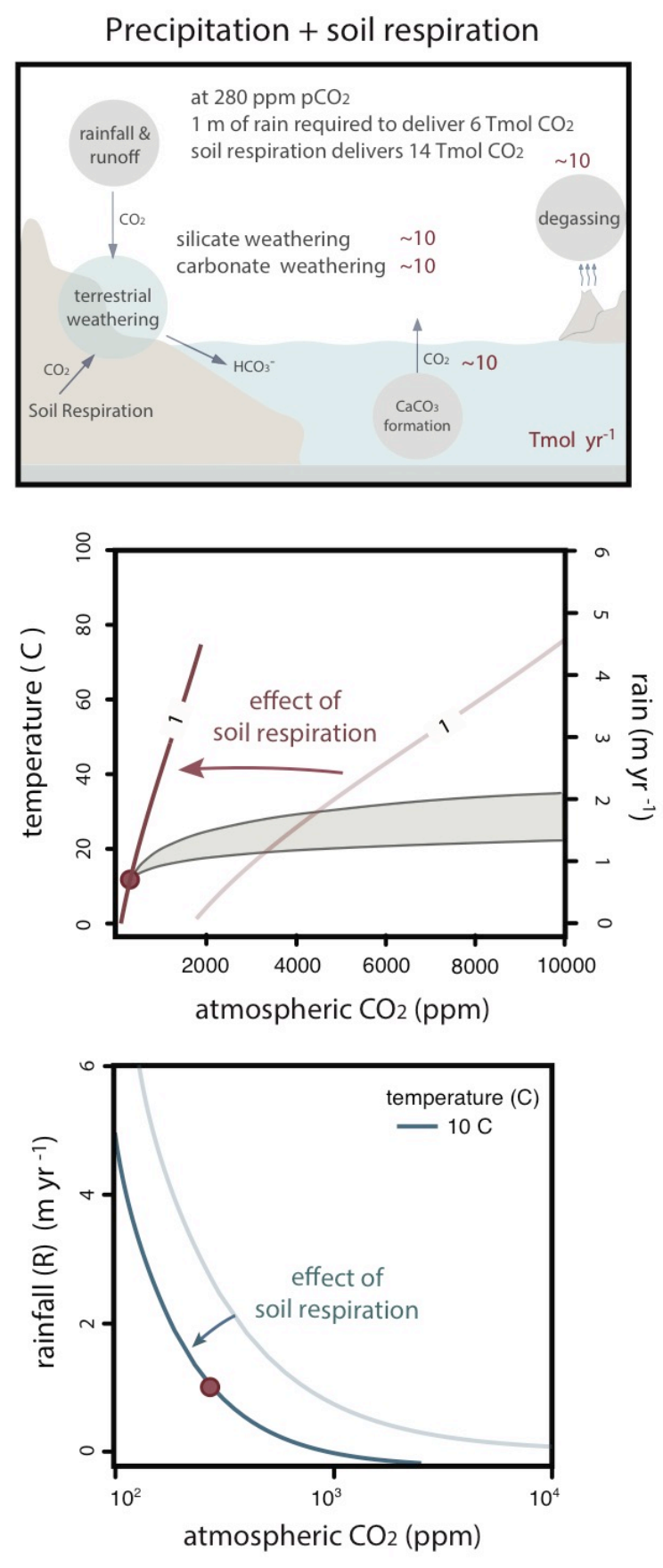

Fig. 8. Sources of acidity for terrestrial silicate weathering: contributions from rain and soil respiration.

Results from a simple water rock mass balance model exploring the amount of rain required to generate a global terrestrial weathering alkalinity flux of $10 \mathrm{Tmol} \mathrm{yr}^{-1}$ through terrestrial silicate weathering. New $\mathrm{CO}_{2}$ 
input into the system is set at $10 \mathrm{Tmol} \mathrm{yr}^{-1}$ and all infiltrating $\mathrm{CO}_{2}$ is assumed to be neutralized. We specify that $50 \%$ of $\mathrm{CO}_{2}$ neutralization occurs through the weathering of carbonate rock, meaning that $20 \mathrm{Tmol} \mathrm{yr}^{-1}$ of $\mathrm{CO}_{2}$ has to be delivered to the terrestrial environment. Red circle indicates preindustrial values of rainfall $=1 \mathrm{~m} \mathrm{yr}^{-1}$, temperature $=12{ }^{\circ} \mathrm{C}$ and atmospheric $\mathrm{pCO} 2=280 \mathrm{ppm}$. This model assumes quantitative neutralization of rainwater through weathering. The model outputs indicate that at $\mathrm{pCO}_{2}$ levels of $280 \mathrm{ppm}$, $10 \mathrm{~m} \mathrm{yr}^{-1}$ of rainfall is required to neutralize volcanic $\mathrm{CO}_{2}$ if here was no soil respiration. This is roughly an order of magnitude higher than modern average annual rainfall estimates. To achieve an annual rainfall estimate of $\sim 1 \mathrm{~m} \mathrm{yr}^{-1}$, this requires that rain supplies only $3 \mathrm{Tmol} \mathrm{yr}^{-1}$ of $\mathrm{CO}_{2}$ for silicate weathering (right panel). The remaining $7 \mathrm{Tmol} \mathrm{yr}^{-1}$ of $\mathrm{CO}_{2}$ can be accounted for by acid generation in terrestrial porewaters through soil respiration. This simple model indicates that rainfall is not the dominant source of $\mathrm{CO}_{2}$ for weathering today (red circle does not sit on the red line). However, at high $\mathrm{pCO}_{2}$ conditions the amount of rainfall needed to deliver enough $\mathrm{CO}_{2}$ to the critical zone to ensure a balanced carbon cycle (silicate weathering equal to $\mathrm{CO}_{2}$ outgassing) is significantly less (left panels). Under these conditions, rainfall becomes the dominant source of $\mathrm{CO}_{2}$, and changes in soil respiration will play a smaller role. The gray region indicates possible temperature and $\mathrm{CO}_{2}$ combinations assuming different climate sensitivities $\left(2-4.5{ }^{\circ} \mathrm{C}\right)$ at modern solar luminosity. 

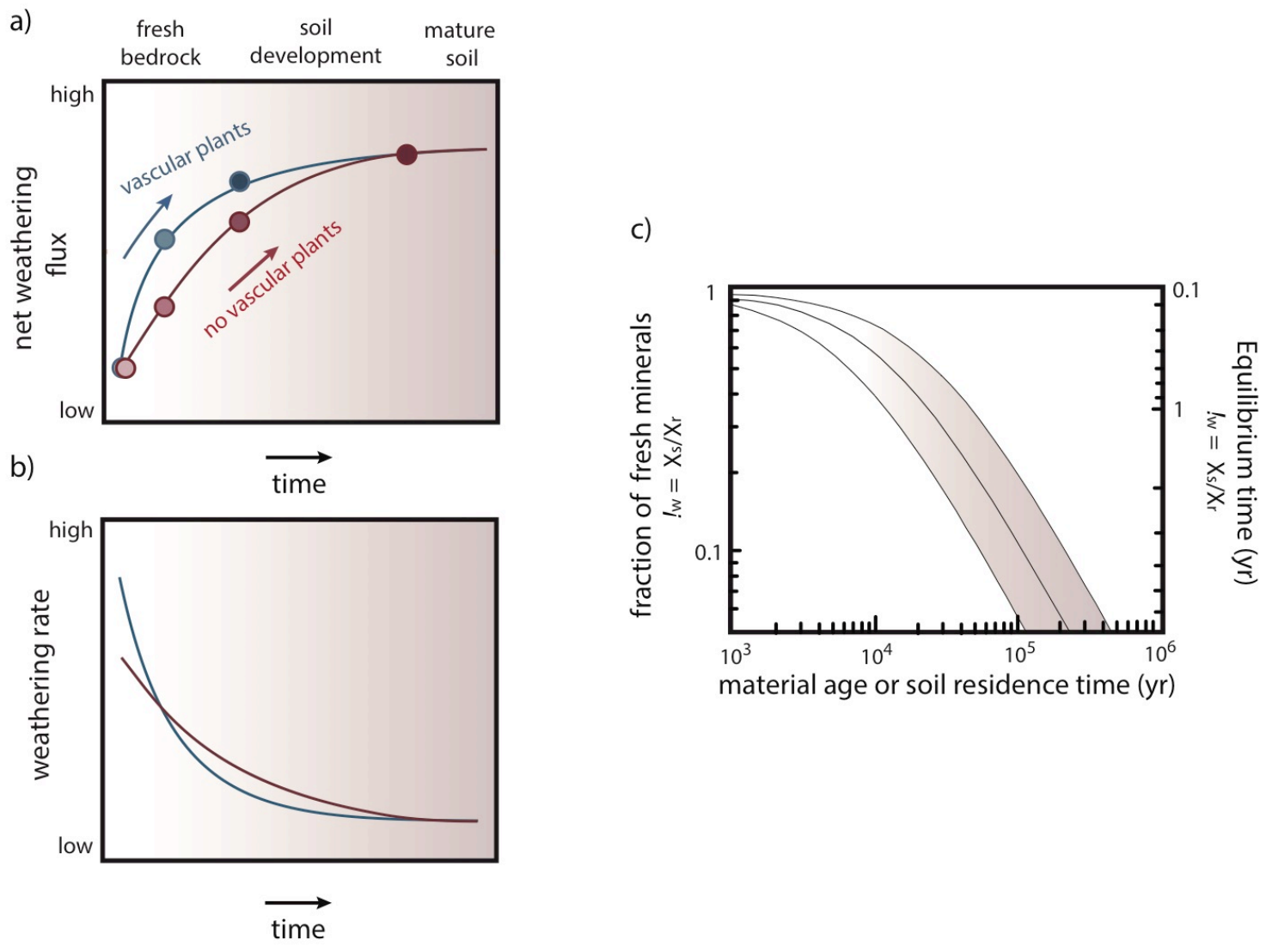

Fig. 9. The effect of land plants on weathering during soil maturation.

Laboratory and field work both indicate that vascular plants accelerate chemical weathering of bedrock over the short time scales in which these experiments are conducted ( $<1$ year). It is important to note that the observed weathering rates are not likely sustainable over the time scale of soil formation (on a time scale of typically thousands of years). As soil profiles mature, they become more chemically depleted (in alkalinity and in fresh material), and therefore chemical weathering fluxes. (Right) Results from a reaction transport model showing the relationship between the material age or soil residence time (horizontal axis) and fresh mineral concentration (Xs/Xr) (Maher and Chamberlain, 2014). The upper and lower bracketing lines represent sensitivity analysis to the weathering rate constant $\left(\mathrm{K}_{\text {eff }}\right)$ of $\mathrm{K}_{\text {eff }} / 2$ and $\mathrm{K}_{\text {eff }} \times 2$ from the best fit value respectively, with all model run results falling between these upper and lower brackets. 


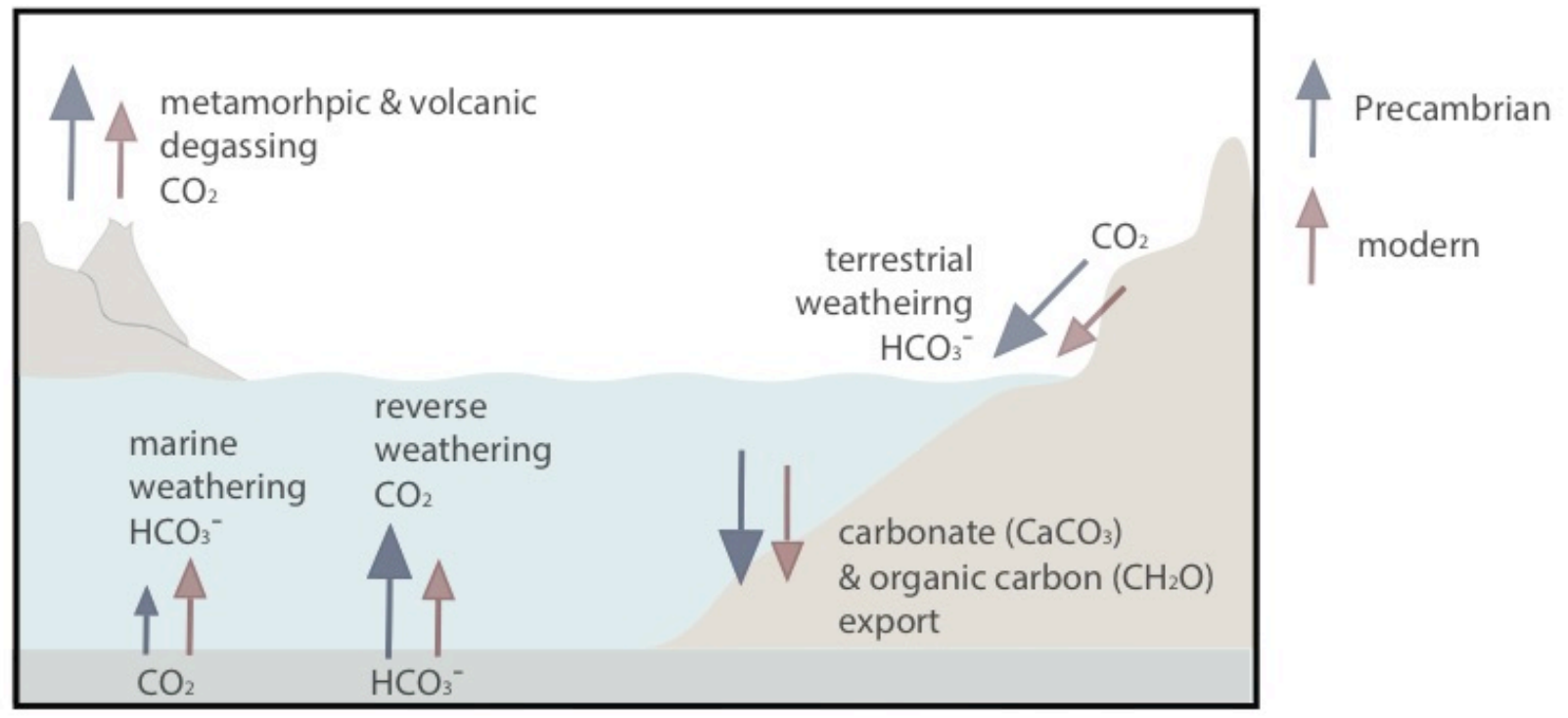

Fig. 10. Cartoon summarizing the modern and Precambrian carbon cycle sources and sinks.

Elevated rates of degassing have been predicted from geophysical models for the Precambrian relative to the modern (e.g., Holland, 2009; O'Neill et al., 2014; Tajika and Matsui, 1992), and on this basis carbonate export tied to silicate weathering must be proportionally larger. Higher dissolved silica and iron levels that are hallmark features of the Precambrian ocean gave rise to conditions that favored enhanced rates of reverse weathering, and dampened marine weathering rates (Isson and Planavsky, 2018). By this framework, it follows that the ratio of terrestrial to marine silicate weathering rates would have been higher in the Precambrian. 
Ague, J. J., 2003, Fluid infiltration and transport of major, minor, and trace elements during regional metamorphism of carbonate rocks, Wepawaug Schist, Connecticut, USA: American Journal of Science, v. 303, no. 9, p. 753-816.

Ague, J. J., and Nicolescu, S., 2014, Carbon dioxide released from subduction zones by fluidmediated reactions: Nature Geoscience, v. 7, no. 5, p. 355.

Algeo, T. J., Berner, R. A., Maynard, J. B., and Scheckler, S. E., 1995, Late Devonian oceanic anoxic events and biotic crises:"rooted" in the evolution of vascular land plants: GSA today, v. 5, no. 3, p. 45-66.

Aloisi, G., Wallmann, K., Drews, M., and Bohrmann, G., 2004, Evidence for the submarine weathering of silicate minerals in Black Sea sediments: possible implications for the marine Li and B cycles: Geochemistry, Geophysics, Geosystems, v. 5, no. 4.

Alt, J. C., and Teagle, D. A., 1999, The uptake of carbon during alteration of ocean crust: Geochimica et Cosmochimica Acta, v. 63, no. 10, p. 1527-1535.

Bachan, A., and Kump, L. R., 2015, The rise of oxygen and siderite oxidation during the Lomagundi Event: Proceedings of the National Academy of Sciences, p. 201422319.

Baldermann, A., Warr, L., Letofsky-Papst, I., and Mavromatis, V., 2015, Substantial iron sequestration during green-clay authigenesis in modern deep-sea sediments: Nature Geoscience.

Baldermann, A., Warr, L. N., Grathoff, G. H., and Dietzel, M., 2013, The rate and mechanism of deep-sea glauconite formation at the Ivory Coast-Ghana marginal ridge: Clays and Clay Minerals, v. 61, no. 3, p. 258-276.

Becker, J. A., Bickle, M. J., Galy, A., and Holland, T. J., 2008, Himalayan metamorphic CO2 fluxes: Quantitative constraints from hydrothermal springs: Earth and Planetary Science Letters, v. 265, no. 3-4, p. 616-629.

Bekker, A., Planavsky, N., Rasmussen, B., Krapez, B., Hofmann, A., Slack, J., Rouxel, O., and Konhauser, K., 2014, Iron formations: Their origins and implications for ancient seawater chemistry, Treatise on geochemistry, Volume 12, Elsevier, p. 561-628.

Berner, E. K., and Berner, R. A., 2012, Global environment: water, air, and geochemical cycles, Princeton University Press.

Berner, R. A., 1992, Weathering, plants, and the long-term carbon cycle: Geochimica et Cosmochimica Acta, v. 56, no. 8, p. 3225-3231.

-, 1997, The rise of plants and their effect on weathering and atmospheric C02: Science, v. 276, no. 5312, p. 544-546.

-, 1998, The carbon cycle and carbon dioxide over Phanerozoic time: the role of land plants: Philosophical Transactions of the Royal Society of London B: Biological Sciences, v. 353, no. 1365 , p. $75-82$.

-, 2004, The Phanerozoic Carbon Cycle: CO2 and 02, Oxford University Press.

Berner, R. A., and Caldeira, K., 1997, The need for mass balance and feedback in the geochemical carbon cycle: Geology, v. 25, no. 10, p. 955-956.

Berner, R. A., Lasaga, A. C., and Garrels, R. M., 1983, The carbonate-silicate geochemical cycle and its effect on atmospheric carbon dioxide over the past 100 million years: Am J Sci, v. 283, p. 641-683.

Bhattacharyya, D. P., 1983, Origin of berthierine in ironstones: Clays and Clay Minerals, v. 31, no. 3, p. 173-182. 
Bickle, M., 1996, Metamorphic decarbonation, silicate weathering and the long-term carbon cycle: Terra Nova, v. 8, no. 3, p. 270-276.

Blum, M., and Pecha, M., 2014, Mid-Cretaceous to Paleocene North American drainage reorganization from detrital zircons: Geology, v. 42, no. 7, p. 607-610.

Blundy, J., Cashman, K. V., Rust, A., and Witham, F., 2010, A case for C02-rich arc magmas: Earth and Planetary Science Letters, v. 290, no. 3-4, p. 289-301.

Bluth, G. J., and Kump, L. R., 1994, Lithologic and climatologic controls of river chemistry: Geochimica et Cosmochimica Acta, v. 58, no. 10, p. 2341-2359.

Bluth, G. J. S., and Kump, L. R., 1991, Phanerozoic paleogeology: American Journal of Science, v. 291, no. 3, p. 284-308.

Bormann, B. T., Wang, D., Snyder, M. C., Bormann, F. H., Benoit, G., and April, R., 1998, Rapid, plant-induced weathering in an aggrading experimental ecosystem: Biogeochemistry, $\mathrm{v}$. 43, no. 2, p. 129-155.

Brady, P. V., and Gíslason, S. R., 1997, Seafloor weathering controls on atmospheric CO2 and global climate: Geochimica et Cosmochimica Acta, v. 61, no. 5, p. 965-973.

Brantley, S. L., 2008, Kinetics of mineral dissolution, Kinetics of water-rock interaction, Springer, p. 151-210.

Burgess, S. D., Bowring, S., and Shen, S.-z., 2014, High-precision timeline for Earth's most severe extinction: Proceedings of the National Academy of Sciences, p. 201317692.

Burgess, S. D., and Bowring, S. A., 2015, High-precision geochronology confirms voluminous magmatism before, during, and after Earth's most severe extinction: Science Advances, v. 1, no. 7, p. e1500470.

Burnett, W. C., Bokuniewicz, H., Huettel, M., Moore, W. S., and Taniguchi, M., 2003, Groundwater and pore water inputs to the coastal zone: Biogeochemistry, v. 66, no. 1-2, p. 3-33.

Caldeira, K., 1995, Long-term control of atmospheric carbon dioxide; low-temperature seafloor alteration or terrestrial silicate-rock weathering?: American Journal of Science, v. 295, no. 9, p. 1077-1114.

Caldeira, K., and Kasting, J. F., 1992, The life span of the biosphere revisited: Nature, v. 360, no. 6406, p. 721.

Campbell, I. H., and Allen, C. M., 2008, Formation of supercontinents linked to increases in atmospheric oxygen: Nature Geoscience, v. 1, no. 8, p. 554.

Cao, W., Lee, C.-T. A., and Lackey, J. S., 2017, Episodic nature of continental arc activity since 750 Ma: A global compilation: Earth and Planetary Science Letters, v. 461, p. 85-95.

Capaldi, T. N., Horton, B. K., McKenzie, N. R., Stockli, D. F., and Odlum, M. L., 2017, Sediment provenance in contractional orogens: The detrital zircon record from modern rivers in the Andean fold-thrust belt and foreland basin of western Argentina: Earth and Planetary Science Letters, v. 479, p. 83-97.

Caro, G., Papanastassiou, D., and Wasserburg, G., 2010, 40K-40Ca isotopic constraints on the oceanic calcium cycle: Earth and Planetary Science Letters, v. 296, no. 1-2, p. 124-132.

Caves, J. K., Jost, A. B., Lau, K. V., and Maher, K., 2016, Cenozoic carbon cycle imbalances and a variable weathering feedback: Earth and Planetary Science Letters, v. 450, p. 152-163.

Cawood, P. A., and Buchan, C., 2007, Linking accretionary orogenesis with supercontinent assembly: Earth-Science Reviews, v. 82, no. 3-4, p. 217-256.

Cawood, P. A., Hawkesworth, C., and Dhuime, B., 2012, Detrital zircon record and tectonic setting: Geology, v. 40, no. 10, p. 875-878.

Chamberlin, T. C., 1899, An attempt to frame a working hypothesis of the cause of glacial periods on an atmospheric basis: The Journal of Geology, v. 7, no. 6, p. 545-584. 
Chan, L., Edmond, J., Thompson, G., and Gillis, K., 1992, Lithium isotopic composition of submarine basalts: implications for the lithium cycle in the oceans: Earth and Planetary Science Letters, v. 108, no. 1, p. 151-160.

Chan, L.-H., Alt, J. C., and Teagle, D. A., 2002, Lithium and lithium isotope profiles through the upper oceanic crust: a study of seawater-basalt exchange at ODP Sites 504B and 896A: Earth and Planetary Science Letters, v. 201, no. 1, p. 187-201.

Chan, L.-H., and Kastner, M., 2000, Lithium isotopic compositions of pore fluids and sediments in the Costa Rica subduction zone: implications for fluid processes and sediment contribution to the arc volcanoes: Earth and Planetary Science Letters, v. 183, no. 1, p. 275-290.

Chavrit, D., Humler, E., and Grasset, O., 2014, Mapping modern CO2 fluxes and mantle carbon content all along the mid-ocean ridge system: Earth and Planetary Science Letters, v. 387, p. 229-239.

Chen, Y., and Brantley, S. L., 1997, Temperature-and pH-dependence of albite dissolution rate at acid pH: Chemical Geology, v. 135, no. 3-4, p. 275-290.

Chiodini, G., Frondini, F., Cardellini, C., Parello, F., and Peruzzi, L., 2000, Rate of diffuse carbon dioxide Earth degassing estimated from carbon balance of regional aquifers: the case of central Apennine, Italy: Journal of Geophysical Research: Solid Earth, v. 105, no. B4, p. 8423-8434.

Cho, H.-M., Kim, G., Kwon, E. Y., Moosdorf, N., Garcia-Orellana, J., and Santos, I. R., 2018, Radium tracing nutrient inputs through submarine groundwater discharge in the global ocean: Scientific reports, v. 8, no. 1, p. 2439.

Cho, H. M., and Kim, G., 2016, Determining groundwater Ra end-member values for the estimation of the magnitude of submarine groundwater discharge using Ra isotope tracers: Geophysical Research Letters, v. 43, no. 8, p. 3865-3871.

Coogan, L. A., and Dosso, S. E., 2015, Alteration of ocean crust provides a strong temperature dependent feedback on the geological carbon cycle and is a primary driver of the Srisotopic composition of seawater: Earth and Planetary Science Letters, v. 415, p. 38-46.

Coogan, L. A., and Gillis, K. M., 2013, Evidence that low-temperature oceanic hydrothermal systems play an important role in the silicate-carbonate weathering cycle and longterm climate regulation: Geochemistry, Geophysics, Geosystems, v. 14, no. 6, p. 17711786.

-, 2018, Low-Temperature Alteration of the Seafloor: Impacts on Ocean Chemistry: Annual Review of Earth and Planetary Sciences, v. 46, p. 21-45.

Coogan, L. A., Parrish, R. R., and Roberts, N. M., 2016, Early hydrothermal carbon uptake by the upper oceanic crust: Insight from in situ U-Pb dating: Geology, v. 44, no. 2, p. 147-150.

D’Antonio, M., Ibarra, D. E., and Boyce, C. K., 2019, Land plant evolution decreased, rather than increased, weathering rates: Geology.

D’Errico, M. E., Lackey, J. S., Surpless, B. E., Loewy, S. L., Wooden, J. L., Barnes, J. D., Strickland, A., and Valley, J. W., 2012, A detailed record of shallow hydrothermal fluid flow in the Sierra Nevada magmatic arc from low- $\delta 180$ skarn garnets: Geology, v. 40, no. 8, p. 763766.

Dasgupta, R., 2013, Ingassing, storage, and outgassing of terrestrial carbon through geologic time: Reviews in Mineralogy and Geochemistry, v. 75, no. 1, p. 183-229.

Dasgupta, R., and Hirschmann, M. M., 2006, Melting in the Earth's deep upper mantle caused by carbon dioxide: Nature, v. 440, no. 7084, p. 659. 
1030 -, 2010, The deep carbon cycle and melting in Earth's interior: Earth and Planetary Science

1031 Letters, v. 298, no. 1-2, p. 1-13.

1032 Dole, S., 1964, Habitable planets for man, New York, Blaisdell Pub: Co.[1964].

1033

1034

1035

1036

1037

1038

1039

1040

1041

1042

1043

1044

1045

1046

1047

1048

1049

1050

1051

1052

1053

1054

1055

1056

1057

1058

1059

1060

1061

1062

1063

1064

1065

1066

1067

1068

1069

1070

1071

1072

1073

1074

1075

1076

Drever, J. I., 1994, The effect of land plants on weathering rates of silicate minerals: Geochimica et Cosmochimica Acta, v. 58, no. 10, p. 2325-2332.

Duncan, M. S., and Dasgupta, R., 2014, CO2 solubility and speciation in rhyolitic sediment partial melts at 1.5-3.0 GPa-implications for carbon flux in subduction zones: Geochimica et Cosmochimica Acta, v. 124, p. 328-347.

Edmond, J. M., and Huh, Y., 2003, Non-steady state carbonate recycling and implications for the evolution of atmospheric PC02: Earth and Planetary Science Letters, v. 216, no. 1-2, p. 125-139.

Ehlert, C., Doering, K., Wallmann, K., Scholz, F., Sommer, S., Grasse, P., Geilert, S., and Frank, M., 2016, Stable silicon isotope signatures of marine pore waters-Biogenic opal dissolution versus authigenic clay mineral formation: Geochimica et Cosmochimica Acta, v. 191, p. 102-117.

Evans, D. A., 2013, Reconstructing pre-Pangean supercontinents: Bulletin, v. 125, no. 11-12, p. 1735-1751.

Ferry, J. M., 1988, Infiltration-driven metamorphism in northern New England, USA: Journal of Petrology, v. 29, no. 6, p. 1121-1159.

France-Lanord, C., and Derry, L. A., 1997, Organic carbon burial forcing of the carbon cycle from Himalayan erosion: Nature, v. 390, no. 6655, p. 65.

Francois, L. M., and Walker, J. C., 1992, Modelling the Phanerozoic carbon cycle and climate: constraints from the $87 \mathrm{Sr} / 86 \mathrm{Sr}$ isotopic ratio of seawater: Am. J. Sci, v. 292, no. 2, p. 81135.

Gaillardet, J., Dupré, B., Louvat, P., and Allegre, C., 1999, Global silicate weathering and CO 2 consumption rates deduced from the chemistry of large rivers: Chemical geology, v. 159 , no. 1, p. 3-30.

Galy, V., France-Lanord, C., Beyssac, O., Faure, P., Kudrass, H., and Palhol, F., 2007, Efficient organic carbon burial in the Bengal fan sustained by the Himalayan erosional system: Nature, v. 450, no. 7168, p. 407.

Galy, V., France-Lanord, C., Beyssac, O., Lartiges, B., and Rhaman, M., 2010, Organic carbon cycling during Himalayan erosion: processes, fluxes and consequences for the global carbon cycle, Climate Change and Food Security in South Asia, Springer, p. 163-181.

Garrels, R. M., 1965, Silica: role in the buffering of natural waters: Science, v. 148, no. 3666, p. 69-69.

Gehrels, G., 2014, Detrital zircon U-Pb geochronology applied to tectonics: Annual Review of Earth and Planetary Sciences, v. 42, p. 127-149.

Gibling, M. R., and Davies, N. S., 2012, Palaeozoic landscapes shaped by plant evolution: Nature Geoscience, v. 5, no. 2, p. 99.

Gillis, K., and Coogan, L., 2011, Secular variation in carbon uptake into the ocean crust: Earth and Planetary Science Letters, v. 302, no. 3, p. 385-392.

Gorman, P. J., Kerrick, D., and Connolly, J., 2006, Modeling open system metamorphic decarbonation of subducting slabs: Geochemistry, Geophysics, Geosystems, v. 7, no. 4.

Gough, D., 1981, Solar interior structure and luminosity variations, Physics of Solar Variations, Springer, p. 21-34.

Grassi, D., and Schmidt, M. W., 2011, The melting of carbonated pelites from 70 to $700 \mathrm{~km}$ depth: Journal of Petrology, v. 52, no. 4, p. 765-789. 
1077

1078

1079

1080

1081

1082

1083

1084

1085

1086

1087

1088

1089

1090

1091

1092

1093

1094

1095

1096

1097

1098

1099

1100

1101

1102

1103

1104

1105

1106

1107

1108

1109

1110

1111

1112

1113

1114

1115

1116

1117

1118

1119

1120

1121

1122

Griffiths, R., Baham, J., and Caldwell, B., 1994, Soil solution chemistry of ectomycorrhizal mats in forest soil: Soil Biology and Biochemistry, v. 26, no. 3, p. 331-337.

Hart, M. H., 1978, The evolution of the atmosphere of the Earth: Icarus, v. 33, no. 1, p. 23-39.

Hartmann, J., and Moosdorf, N., 2012, The new global lithological map database GLiM: A representation of rock properties at the Earth surface: Geochemistry, Geophysics, Geosystems, v. 13, no. 12.

Hartmann, J., Moosdorf, N., Lauerwald, R., Hinderer, M., and West, A. J., 2014, Global chemical weathering and associated P-release-The role of lithology, temperature and soil properties: Chemical Geology, v. 363, p. 145-163.

Hasterok, D., 2013, Global patterns and vigor of ventilated hydrothermal circulation through young seafloor: Earth and Planetary Science Letters, v. 380, p. 12-20.

Hazen, R. M., Sverjensky, D. A., Azzolini, D., Bish, D. L., Elmore, S. C., Hinnov, L., and Milliken, R. E., 2013, Clay mineral evolution: American Mineralogist, v. 98, no. 11-12, p. 2007-2029.

Helo, C., Longpré, M.-A., Shimizu, N., Clague, D. A., and Stix, J., 2011, Explosive eruptions at midocean ridges driven by CO 2-rich magmas: Nature Geoscience, v. 4, no. 4, p. 260.

Higgins, J. A., and Schrag, D. P., 2015, The Mg isotopic composition of Cenozoic seawaterevidence for a link between Mg-clays, seawater $\mathrm{Mg} / \mathrm{Ca}$, and climate: Earth and Planetary Science Letters, v. 416, p. 73-81.

Hilton, D. R., Fischer, T. P., and Marty, B., 2002, Noble gases and volatile recycling at subduction zones: Reviews in mineralogy and geochemistry, v. 47, no. 1, p. 319-370.

Hinrichs, K.-U., and Boetius, A., 2002, The anaerobic oxidation of methane: new insights in microbial ecology and biogeochemistry, Ocean margin systems, Springer, p. 457-477.

Hirschmann, M. M., 2018, Comparative deep Earth volatile cycles: The case for $\mathrm{C}$ recycling from exosphere/mantle fractionation of major ( $\mathrm{H} 2 \mathrm{O}, \mathrm{C}, \mathrm{N}$ ) volatiles and from $\mathrm{H} 2 \mathrm{O} / \mathrm{Ce}$, C02/Ba, and CO2/Nb exosphere ratios: Earth and Planetary Science Letters, v. 502, p. 262-273.

Hoffman, P. F., Abbot, D. S., Ashkenazy, Y., Benn, D. I., Brocks, J. J., Cohen, P. A., Cox, G. M., Creveling, J. R., Donnadieu, Y., and Erwin, D. H., 2017, Snowball Earth climate dynamics and Cryogenian geology-geobiology: Science Advances, v. 3, no. 11, p. e1600983.

Högbom, A., 1894, On the probability of secular variations of atmospheric carbon dioxide (in Swedish): Svensk kemisk Tidskrift, v. 6, p. 169-176.

Holland, H. D., 1965, The history of ocean water and its effect on the chemistry of the atmosphere: Proceedings of the National Academy of Sciences, v. 53, no. 6, p. 11731183.

,- 1984 , The chemical evolution of the atmosphere and oceans, Princeton University Press.

-, 2002, Volcanic gases, black smokers, and the Great Oxidation Event: Geochimica et Cosmochimica Acta, v. 66, no. 21, p. 3811-3826.

-, 2005, Sea level, sediments and the composition of seawater: American Journal of Science, v. 305, no. 3, p. 220-239.

-, 2009, Why the atmosphere became oxygenated: a proposal: Geochimica et Cosmochimica Acta, v. 73, no. 18, p. 5241-5255.

Hoyle, F., 1957, The black cloud (pp. 26-27), London: Penguin.

Ilyinskaya, E., Mobbs, S., Burton, R., Burton, M., Pardini, F., Pfeffer, M. A., Purvis, R., Lee, J., Bauguitte, S., and Brooks, B., 2018, Globally significant CO2 emissions from Katla, a subglacial volcano in Iceland: Geophysical Research Letters, v. 45, no. 19, p. 10,332310,341 . 
Isson, T. T., and Planavsky, N. J., 2018, Reverse weathering as a long-term stabilizer of marine pH and planetary climate: Nature, v. 560, no. 7719, p. 471-475.

Jagoutz, O., Macdonald, F. A., and Royden, L., 2016, Low-latitude arc-continent collision as a driver for global cooling: Proceedings of the National Academy of Sciences, v. 113, no. 18, p. 4935-4940.

Johnson, J. E., Muhling, J. R., Cosmidis, J., Rasmussen, B., and Templeton, A. S., 2018, Low-Fe (III) Greenalite Was a Primary Mineral from Neoarchean Oceans: Geophysical Research Letters, v. 45, no. 7, p. 3182-3192.

Kasting, J. F., 1987, Theoretical constraints on oxygen and carbon dioxide concentrations in the Precambrian atmosphere: Precambrian research, v. 34, no. 3, p. 205-229.

-, 2019, The Goldilocks planet? How silicate weathering maintains Earth "just right": Elements: An International Magazine of Mineralogy, Geochemistry, and Petrology, v. 15, no. 4, p. 235-240.

Kasting, J. F., Whitmire, D. P., and Reynolds, R. T., 1993, Habitable zones around main sequence stars: Icarus, v. 101, no. 1, p. 108-128.

Kelemen, P. B., Hanghøj, K., and Greene, A., 2003, One view of the geochemistry of subductionrelated magmatic arcs, with an emphasis on primitive andesite and lower crust: Treatise on geochemistry, v. 3, p. 659.

Kelemen, P. B., and Manning, C. E., 2015, Reevaluating carbon fluxes in subduction zones, what goes down, mostly comes up: Proceedings of the National Academy of Sciences, p. 201507889.

Keller, C., and Wood, B., 1993, Possibility of chemical weathering before the advent of vascular land plants: Nature, v. 364, no. 6434, p. 223-225.

Kerrick, D., and Caldeira, K., 1993, Paleoatmospheric consequences of CO2 released during early Cenozoic regional metamorphism in the Tethyan orogen: Chemical Geology, v. 108 , no. $1-4$, p. $201-230$.

-, 1999, Was the Himalayan orogen a climatically significant coupled source and sink for atmospheric CO2 during the Cenozoic?: Earth and Planetary Science Letters, v. 173, no. 3, p. 195-203.

Kerrick, D., and Connolly, J., 2001, Metamorphic devolatilization of subducted marine sediments and the transport of volatiles into the Earth's mantle: Nature, v. 411, no. 6835, p. 293.

Kerrick, D. M., and Caldeira, K., 1998, Metamorphic CO2 degassing from orogenic belts: Chemical Geology, v. 145, no. 3-4, p. 213-232.

Kim, J. H., Torres, M. E., Haley, B. A., Ryu, J. S., Park, M. H., Hong, W. L., and Choi, J., 2016, Marine silicate weathering in the anoxic sediment of the Ulleung Basin: Evidence and consequences: Geochemistry, Geophysics, Geosystems, v. 17, no. 8, p. 3437-3453.

Korenaga, J., 2018, Crustal evolution and mantle dynamics through Earth history: Phil. Trans. R. Soc. A, v. 376, no. 2132, p. 20170408.

Krissansen-Totton, J., and Catling, D. C., 2017, Constraining climate sensitivity and continental versus seafioor weathering using an inverse geological carbon cycle model: NATURE, v. 8, no. 15423 , p. 1.

$\mathrm{Ku}, \mathrm{T}$., and Walter, L., 2003, Syndepositional formation of Fe-rich clays in tropical shelf sediments, San Blas Archipelago, Panama: Chemical Geology, v. 197, no. 1-4, p. 197-213.

Kump, L. R., 2018, Prolonged Late Permian-Early Triassic hyperthermal: failure of climate regulation?: Philosophical transactions. Series A, Mathematical, physical, and engineering sciences, v. 376, no. 2130. 
1170 Kump, L. R., and Arthur, M. A., 1997, Global chemical erosion during the Cenozoic:

Kump, L. R., Brantley, S. L., and Arthur, M. A., 2000, Chemical weathering, atmospheric CO2, and climate: Annual Review of Earth and Planetary Sciences, v. 28, no. 1, p. 611-667.

Kwon, E. Y., Kim, G., Primeau, F., Moore, W. S., Cho, H. M., DeVries, T., Sarmiento, J. L., Charette, M. A., and Cho, Y. K., 2014, Global estimate of submarine groundwater discharge based on an observationally constrained radium isotope model: Geophysical Research Letters, v. 41, no. 23, p. 8438-8444.

Laakso, T. A., and Schrag, D. P., 2014, Regulation of atmospheric oxygen during the Proterozoic: Earth and Planetary Science Letters, v. 388, p. 81-91.

Laruelle, G. G., Roubeix, V., Sferratore, A., Brodherr, B., Ciuffa, D., Conley, D., Dürr, H., Garnier, J., Lancelot, C., and Le Thi Phuong, Q., 2009, Anthropogenic perturbations of the silicon cycle at the global scale: Key role of the land-ocean transition: Global biogeochemical cycles, v. 23, no. 4.

Le Voyer, M., Kelley, K. A., Cottrell, E., and Hauri, E., 2017, Heterogeneity in mantle carbon content from CO 2-undersaturated basalts: Nature Communications, v. 8, p. 14062.

Lee, C.-T. A., and Bachmann, O., 2014, How important is the role of crystal fractionation in making intermediate magmas? Insights from $\mathrm{Zr}$ and $\mathrm{P}$ systematics: Earth and Planetary Science Letters, v. 393, p. 266-274.

Lee, C.-T. A., and Lackey, J. S., 2015, Global continental arc flare-ups and their relation to longterm greenhouse conditions: Elements, v. 11, no. 2, p. 125-130.

Lee, C.-T. A., Shen, B., Slotnick, B. S., Liao, K., Dickens, G. R., Yokoyama, Y., Lenardic, A., Dasgupta, R., Jellinek, M., and Lackey, J. S., 2013, Continental arc-island arc fluctuations, growth of crustal carbonates, and long-term climate change: Geosphere, v. 9, no. 1, p. 21-36.

Lee, C.-T. A., Thurner, S., Paterson, S., and Cao, W., 2015, The rise and fall of continental arcs: Interplays between magmatism, uplift, weathering, and climate: Earth and Planetary Science Letters, v. 425, p. 105-119.

Lenton, T. M., 2001, The role of land plants, phosphorus weathering and fire in the rise and regulation of atmospheric oxygen: Global Change Biology, v. 7, no. 6, p. 613-629.

Li, G., and Elderfield, H., 2013, Evolution of carbon cycle over the past 100 million years: Geochimica et Cosmochimica Acta, v. 103, p. 11-25.

Li, K.-F., Pahlevan, K., Kirschvink, J. L., and Yung, Y. L., 2009, Atmospheric pressure as a natural climate regulator for a terrestrial planet with a biosphere: Proceedings of the National Academy of Sciences, v. 106, no. 24, p. 9576-9579.

Li, L., Maher, K., Navarre-Sitchler, A., Druhan, J., Meile, C., Lawrence, C., Moore, J., Perdrial, J., Sullivan, P., and Thompson, A., 2017, Expanding the role of reactive transport models in critical zone processes: Earth-science reviews, v. 165, p. 280-301.

Li, Y.-H., 2000, A compendium of geochemistry: from solar nebula to the human brain, Princeton University Press.

Liu, Y., Yamanaka, T., Zhou, X., Tian, F., and Ma, W., 2014, Combined use of tracer approach and numerical simulation to estimate groundwater recharge in an alluvial aquifer system: A case study of Nasunogahara area, central Japan: Journal of hydrology, v. 519, p. 833847.

Loucaides, S., Michalopoulos, P., Presti, M., Koning, E., Behrends, T., and Van Cappellen, P., 2010, Seawater-mediated interactions between diatomaceous silica and terrigenous sediments: results from long-term incubation experiments: Chemical Geology, v. 270, no. 1-4, p. 68-79. 
Lovelock, J. E., and Kump, L. R., 1994, Failure of climate regulation in a geophysiological model: Nature, v. 369, no. 6483, p. 732.

Lovelock, J. E., and Margulis, L., 1974, Atmospheric homeostasis by and for the biosphere: the Gaia hypothesis: Tellus, v. 26, no. 1-2, p. 2-10.

Lovelock, J. E., and Whitfield, M., 1982, Life span of the biosphere: Nature, v. 296, no. 5857, p. 561-563.

Lowenstein, T. K., Hardie, L. A., Timofeeff, M. N., and Demicco, R. V., 2003, Secular variation in seawater chemistry and the origin of calcium chloride basinal brines: Geology, v. 31, no. 10, p. 857-860.

Mackenzie, F., Ristvet, B., Thorstenson, D., Lerman, A., and Leeper, R., 1981, Reverse weathering and chemical mass balance in a coastal environment.

Mackenzie, F. T., and Garrels, R., 1971, Evolution of sedimentary rocks, Norton New York.

Mackenzie, F. T., and Garrels, R. M., 1965, Silicates: reactivity with sea water: Science, v. 150, no. 3692, p. 57-58.

-, 1966a, Chemical mass balance between rivers and oceans: American Journal of Science, v. 264, no. 7, p. 507-525.

-, 1966b, Silica-bicarbonate balance in the ocean and early diagenesis: Journal of Sedimentary Petrology, v. 36, no. 4.

Mackin, J. E., and Aller, R. C., 1984, Dissolved Al in sediments and waters of the East China Sea: Implications for authigenic mineral formation: Geochimica et Cosmochimica Acta, v. 48, no. 2, p. 281-297.

-, 1986, The effects of clay mineral reactions on dissolved Al distributions in sediments and waters of the Amazon continental shelf: Continental Shelf Research, v. 6, no. 1, p. 245262.

Maher, K., and Chamberlain, C., 2014, Hydrologic regulation of chemical weathering and the geologic carbon cycle: science, v. 343, no. 6178, p. 1502-1504.

Maher, K., DePaolo, D. J., and Lin, J. C.-F., 2004, Rates of silicate dissolution in deep-sea sediment: in situ measurement using $234 \mathrm{U} / 238 \mathrm{U}$ of pore fluids: Geochimica et Cosmochimica Acta, v. 68, no. 22, p. 4629-4648.

Maher, K., Steefel, C. I., DePaolo, D. J., and Viani, B. E., 2006, The mineral dissolution rate conundrum: Insights from reactive transport modeling of $U$ isotopes and pore fluid chemistry in marine sediments: Geochimica et Cosmochimica Acta, v. 70, no. 2, p. 337363.

Marty, B., and Tolstikhin, I. N., 1998, CO 2 fluxes from mid-ocean ridges, arcs and plumes: Chemical Geology, v. 145, no. 3, p. 233-248.

März, C., Meinhardt, A.-K., Schnetger, B., and Brumsack, H.-J., 2015, Silica diagenesis and benthic fluxes in the Arctic Ocean: Marine Chemistry, v. 171, p. 1-9.

Mason, B., and Moore, C., 1982, Concentrations in crust, granite, Diabase (basalt), and shale: Principles of Geochemistry, p. 46-47.

Mason, E., Edmonds, M., and Turchyn, A. V., 2017, Remobilization of crustal carbon may dominate volcanic arc emissions: Science, v. 357, no. 6348, p. 290-294.

Matthews, S., Shorttle, O., Rudge, J. F., and Maclennan, J., 2017, Constraining mantle carbon: CO 2-trace element systematics in basalts and the roles of magma mixing and degassing: Earth and Planetary Science Letters, v. 480, p. 1-14.

McKenzie, N. R., Horton, B. K., Loomis, S. E., Stockli, D. F., Planavsky, N. J., and Lee, C.-T. A., 2016, Continental arc volcanism as the principal driver of icehouse-greenhouse variability: Science, v. 352, no. 6284, p. 444-447. 
McKenzie, N. R., Hughes, N. C., Gill, B. C., and Myrow, P. M., 2014, Plate tectonic influences on Neoproterozoic-early Paleozoic climate and animal evolution: Geology, v. 42, no. 2, p. 127-130.

Michalopoulos, P., and Aller, R. C., 1995, Rapid clay mineral formation of Amazon delta sediments: Reverse weathering and oceanic elemental cycles: Science, v. 270, no. 5236, p. 614.

-, 2004, Early diagenesis of biogenic silica in the Amazon delta: alteration, authigenic clay formation, and storage: Geochimica et Cosmochimica Acta, v. 68, no. 5, p. 1061-1085.

Michalopoulos, P., Aller, R. C., and Reeder, R. J., 2000, Conversion of diatoms to clays during early diagenesis in tropical, continental shelf muds: Geology, v. 28, no. 12, p. 1095-1098.

Mills, B. J., Scotese, C. R., Walding, N. G., Shields, G. A., and Lenton, T. M., 2017, Elevated CO 2 degassing rates prevented the return of Snowball Earth during the Phanerozoic: Nature communications, v. 8, no. 1, p. 1110.

Misra, S., and Froelich, P. N., 2012, Lithium isotope history of Cenozoic seawater: changes in silicate weathering and reverse weathering: Science, v. 335, no. 6070, p. 818-823.

Mojzsis, S. J., Harrison, T. M., and Pidgeon, R. T., 2001, Oxygen-isotope evidence from ancient zircons for liquid water at the Earth's surface 4,300 Myr ago: Nature, v. 409, no. 6817, p. 178.

Moore, W. S., Sarmiento, J. L., and Key, R. M., 2008, Submarine groundwater discharge revealed by 228 Ra distribution in the upper Atlantic Ocean: Nature Geoscience, v. 1, no. 5, p. 309.

Moulton, K. L., and Berner, R. A., 1998, Quantification of the effect of plants on weathering: Studies in Iceland: Geology, v. 26, no. 10, p. 895-898.

Mulligan, A. E., and Charette, M. A., 2009, Groundwater flow to the coastal ocean: Elements of Physical Oceanography: A Derivative of the Encyclopedia of Ocean Sciences, v. 465.

Nesbitt, B. E., Mendoza, C. A., and Kerrick, D. M., 1995, Surface fluid convection during Cordilleran extension and the generation of metamorphic $\mathrm{CO} 2$ contributions to Cenozoic atmospheres: Geology, v. 23, no. 2, p. 99-101.

O'Neill, C., Lenardic, A., Höink, T., and Coltice, N., 2014, Mantle convection and outgassing on terrestrial planets, Comparative Climatology of Terrestrial Planets, 473 p.:

Ozaki, K., Reinhard, C. T., and Tajika, E., 2019, A sluggish mid-Proterozoic biosphere and its effect on Earth's redox balance: Geobiology, v. 17, no. 1, p. 3-11.

Penman, D. E., 2016, Silicate weathering and North Atlantic silica burial during the PaleoceneEocene Thermal Maximum: Geology, v. 44, no. 9, p. 731-734.

Piccoli, F., Brovarone, A. V., Beyssac, O., Martinez, I., Ague, J. J., and Chaduteau, C., 2016, Carbonation by fluid-rock interactions at high-pressure conditions: implications for carbon cycling in subduction zones: Earth and Planetary Science Letters, v. 445, p. 146159.

Plank, T., and Manning, C. E., 2019, Subducting carbon: Nature, v. 574, no. 7778, p. 343-352.

Pletsch, T., 2001, Palaeoenvironmental implications of palygorskite clays in Eocene deep-water sediments from the western central Atlantic: Geological Society, London, Special Publications, v. 183, no. 1, p. 307-316.

Poli, S., 2015, Carbon mobilized at shallow depths in subduction zones by carbonatitic liquids: Nature Geoscience, v. 8, no. 8, p. 633.

Presti, M., and Michalopoulos, P., 2008, Estimating the contribution of the authigenic mineral component to the long-term reactive silica accumulation on the western shelf of the Mississippi River Delta: Continental Shelf Research, v. 28, no. 6, p. 823-838. 
1311 Quirk, J., Leake, J. R., Johnson, D. A., Taylor, L. L., Saccone, L., and Beerling, D. J., 2015,

1312

1313

1314

1315

1316

1317

1318

1319

1320

1321

1322

1323

1324

1325

1326

1327

1328

1329

1330

1331

1332

1333

1334

1335

1336

1337

1338

1339

1340

1341

1342

1343

1344

1345

1346

1347

1348

1349

1350

1351

1352

1353

1354

1355

1356

1357 Constraining the role of early land plants in Palaeozoic weathering and global cooling: Proc. R. Soc. B, v. 282, no. 1813, p. 20151115.

Rahman, S., Aller, R., and Cochran, J., 2016, Cosmogenic 32Si as a tracer of biogenic silica burial and diagenesis: Major deltaic sinks in the silica cycle: Geophysical Research Letters, v. 43, no. 13, p. 7124-7132.

-, 2017, The missing silica sink: Revisiting the marine sedimentary Si cycle using cosmogenic 32Si: Global Biogeochemical Cycles, v. 31, no. 10, p. 1559-1578.

Rasmussen, B., Krapež, B., Muhling, J. R., and Suvorova, A., 2015, Precipitation of iron silicate nanoparticles in early Precambrian oceans marks Earth's first iron age: Geology, v. 43, no. 4, p. 303-306.

Rasmussen, B., Meier, D. B., Krapež, B., and Muhling, J. R., 2013, Iron silicate microgranules as precursor sediments to 2.5-billion-year-old banded iron formations: Geology, v. 41, no. 4, p. 435-438.

Rasmussen, B., Muhling, J. R., Suvorova, A., and Krapež, B., 2017, Greenalite precipitation linked to the deposition of banded iron formations downslope from a late Archean carbonate platform: Precambrian Research, v. 290, p. 49-62.

Reeburgh, W., 1993, The role of methylotrophy in the global methane budget: Microbial growth on C-1 compounds, p. 1-14.

Ridgwell, A., 2005, A Mid Mesozoic Revolution in the regulation of ocean chemistry: Marine Geology, v. 217, no. 3, p. 339-357.

Ristvet, B. L., 1978, Reverse weathering reactions within recent nearshore marine sediments, Kaneohe Bay, Oahu [Ph.D.: Northwestern Univ.

Ronov, A., Yaroshevsky, A., and Migdisov, A., 1990, Chemical Composition of the Earth's Crust and Geochemical Balance of Main Elements, Moscow: Nauka, Science Pub. House.(in Russian).

Rosas, J. C., and Korenaga, J., 2018, Rapid crustal growth and efficient crustal recycling in the early Earth: Implications for Hadean and Archean geodynamics: Earth and Planetary Science Letters, v. 494, p. 42-49.

Rugenstein, J. K. C., Ibarra, D. E., and von Blanckenburg, F., 2019, Neogene cooling driven by land surface reactivity rather than increased weathering fluxes: Nature, v. 571, no. 7763, p. 99.

Saal, A. E., Hauri, E. H., Langmuir, C. H., and Perfit, M. R., 2002, Vapour undersaturation in primitive mid-ocean-ridge basalt and the volatile content of Earth's upper mantle: Nature, v. 419, no. 6906, p. 451.

Sagan, C., and Mullen, G., 1972, Earth and Mars: Evolution of atmospheres and surface temperatures: Science, v. 177, no. 4043, p. 52-56.

Scambelluri, M., Bebout, G. E., Belmonte, D., Gilio, M., Campomenosi, N., Collins, N., and Crispini, L., 2016, Carbonation of subduction-zone serpentinite (high-pressure ophicarbonate; Ligurian Western Alps) and implications for the deep carbon cycling: Earth and Planetary Science Letters, v. 441, p. 155-166.

Scholz, F., Hensen, C., Schmidt, M., and Geersen, J., 2013, Submarine weathering of silicate minerals and the extent of pore water freshening at active continental margins: Geochimica et Cosmochimica Acta, v. 100, p. 200-216.

Seiffert, F., Bandow, N., Bouchez, J., Von Blanckenburg, F., and Gorbushina, A., 2014, Microbial colonization of bare rocks: laboratory biofilm enhances mineral weathering: Procedia Earth and Planetary Science, v. 10, p. 123-129. 
Siever, R., 1992, The silica cycle in the Precambrian: Geochimica et Cosmochimica Acta, v. 56, no. 8, p. 3265-3272.

Sillén, L. G., 1961, The physical chemistry of sea water: Oceanography, v. 67, p. 549-581.

-, 1967, The ocean as a chemical system: Science, v. 156, no. 3779, p. 1189-1197.

Skelton, A., 2011, Flux rates for water and carbon during greenschist facies metamorphism: Geology, v. 39, no. 1, p. 43-46.

Solomon, E. A., Kastner, M., Jannasch, H., Robertson, G., and Weinstein, Y., 2008, Dynamic fluid flow and chemical fluxes associated with a seafloor gas hydrate deposit on the northern Gulf of Mexico slope: Earth and Planetary Science Letters, v. 270, no. 1-2, p. 95-105.

Spivack, A. J., and Staudigel, H., 1994, Low-temperature alteration of the upper oceanic crust and the alkalinity budget of seawater: Chemical Geology, v. 115, no. 3-4, p. 239-247.

Stallard, R., and Edmond, J., 1981, Geochemistry of the Amazon: 1. Precipitation chemistry and the marine contribution to the dissolved load at the time of peak discharge: Journal of Geophysical Research: Oceans, v. 86, no. C10, p. 9844-9858.

-, 1983, Geochemistry of the Amazon: 2. The influence of geology and weathering environment on the dissolved load: Journal of Geophysical Research: Oceans, v. 88, no. C14, p. 96719688.

Stallard, R. F., 1985, River chemistry, geology, geomorphology, and soils in the Amazon and Orinoco basins, The chemistry of weathering, Springer, p. 293-316.

Staudigel, H., and Hart, S., 1985, DATING OF OCEAN CRUST HYDROTHERMAL ALTERATIONSTRONTIUM ISOTOPE RATIOS FROM HOLE-504B CARBONATES AND A REINTERPRETATION OF SR ISOTOPE DATA FROM DEEP-SEA DRILLING PROJECT SITES 105, 332, 417, AND 418: Initial Reports of the Deep Sea Drilling Project, v. 83, no. APR, p. 297-303.

Staudigel, H., Hart, S. R., Schmincke, H.-U., and Smith, B. M., 1989, Cretaceous ocean crust at DSDP Sites 417 and 418: Carbon uptake from weathering versus loss by magmatic outgassing: Geochimica et Cosmochimica Acta, v. 53, no. 11, p. 3091-3094.

Stein, C. A., and Stein, S., 1994, Constraints on hydrothermal heat flux through the oceanic lithosphere from global heat flow: Journal of Geophysical Research: Solid Earth, v. 99, no. B2, p. 3081-3095.

Stewart, B. T., Santos, I. R., Tait, D. R., Macklin, P. A., and Maher, D. T., 2015, Submarine groundwater discharge and associated fluxes of alkalinity and dissolved carbon into Moreton Bay (Australia) estimated via radium isotopes: Marine Chemistry, v. 174, p. 112.

Stewart, E., and Ague, J. J., 2018, Infiltration-driven metamorphism, New England, USA: Regional CO 2 fluxes and implications for Devonian climate and extinctions: Earth and Planetary Science Letters, v. 489, p. 123-134.

Stewart, E., Ague, J. J., Ferry, J. M., Schiffries, C. M., Tao, R.-B., Isson, T. T., and Planavsky, N. J., 2019, Carbonation and decarbonation reactions: Implications for planetary habitability, Mineralogical Society of America.

Suchet, P.-A., Probst, J. L., and Ludwig, W., 2003, Worldwide distribution of continental rock lithology: Implications for the atmospheric/soil CO2 uptake by continental weathering and alkalinity river transport to the oceans: Global Biogeochemical Cycles, v. 17, no. 2.

Sun, X., and Turchyn, A. V., 2014, Significant contribution of authigenic carbonate to marine carbon burial: Nature Geoscience, v. 7, no. 3, p. 201.

Szymczycha, B., and Pempkowiak, J., 2015, The Role of Submarine Groundwater Discharge as Material Source to the Baltic Sea, Springer. 
Tajika, E., and Matsui, T., 1992, Evolution of terrestrial proto-CO2 atmosphere coupled with thermal history of the earth: Earth and Planetary Science Letters, v. 113, no. 1-2, p. 251266.

Taniguchi, M., 2002, Tidal effects on submarine groundwater discharge into the ocean: Geophysical Research Letters, v. 29, no. 12, p. 2-1-2-3.

Taniguchi, M., Burnett, W. C., Dulaiova, H., Kontar, E. A., Povinec, P. P., and Moore, W. S., 2006, Submarine groundwater discharge measured by seepage meters in Sicilian coastal waters: Continental Shelf Research, v. 26, no. 7, p. 835-842.

Tatzel, M., von Blanckenburg, F., Oelze, M., Schuessler, J. A., and Bohrmann, G., 2015, The silicon isotope record of early silica diagenesis: Earth and Planetary Science Letters, v. 428, p. 293-303.

Torres, M. A., West, A. J., and Li, G., 2014, Sulphide oxidation and carbonate dissolution as a source of CO2 over geological timescales: Nature, v. 507, no. 7492, p. 346-349.

Tosca, N. J., Guggenheim, S., and Pufahl, P. K., 2016, An authigenic origin for Precambrian greenalite: Implications for iron formation and the chemistry of ancient seawater: Geological Society of America Bulletin, v. 128, no. 3-4, p. 511-530.

Tosca, N. J., Macdonald, F. A., Strauss, J. V., Johnston, D. T., and Knoll, A. H., 2011, Sedimentary talc in Neoproterozoic carbonate successions: Earth and Planetary Science Letters, v. 306, no. 1, p. 11-22.

Tréguer, P. J., and De La Rocha, C. L., 2013, The World Ocean Silica Cycle: Annual Review of Marine Science, v. 5, p. 477-501.

Urey, H. C., 1952, On the early chemical history of the earth and the origin of life: Proceedings of the National Academy of Sciences, v. 38, no. 4, p. 351-363.

Van Der Meer, D. G., Zeebe, R. E., van Hinsbergen, D. J., Sluijs, A., Spakman, W., and Torsvik, T. H., 2014, Plate tectonic controls on atmospheric CO2 levels since the Triassic: Proceedings of the National Academy of Sciences, p. 201315657.

Voice, P. J., Kowalewski, M., and Eriksson, K. A., 2011, Quantifying the timing and rate of crustal evolution: Global compilation of radiometrically dated detrital zircon grains: The Journal of Geology, v. 119, no. 2, p. 109-126.

Von Strandmann, P. A. P., Jenkyns, H. C., and Woodfine, R. G., 2013, Lithium isotope evidence for enhanced weathering during Oceanic Anoxic Event 2: Nature Geoscience, v. 6, no. 8, p. 668.

Walker, J. C., Hays, P., and Kasting, J. F., 1981, A negative feedback mechanism for the long-term stabilization of Earth's surface temperature: Journal of Geophysical Research: Oceans, v. 86, no. C10, p. 9776-9782.

Wallmann, K., and Aloisi, G., 2012, The global carbon cycle: geological processes: Fundamentals of Geobiology, p. 20-35.

Wallmann, K., Aloisi, G., Haeckel, M., Tishchenko, P., Pavlova, G., Greinert, J., Kutterolf, S., and Eisenhauer, A., 2008, Silicate weathering in anoxic marine sediments: Geochimica et Cosmochimica Acta, v. 72, no. 12, p. 2895-2918.

Wallmann, K., Pinero, E., Burwicz, E., Haeckel, M., Hensen, C., Dale, A., and Ruepke, L., 2012, The global inventory of methane hydrate in marine sediments: A theoretical approach: Energies, v. 5, no. 7, p. 2449-2498.

Wilde, S. A., Valley, J. W., Peck, W. H., and Graham, C. M., 2001, Evidence from detrital zircons for the existence of continental crust and oceans on the Earth 4.4 Gyr ago: Nature, v. 409, no. 6817, p. 175. 
1451 Winnick, M. J., and Maher, K., 2018, Relationships between CO2, thermodynamic limits on silicate weathering, and the strength of the silicate weathering feedback: Earth and Planetary Science Letters, v. 485, p. 111-120.

Wortmann, U. G., and Paytan, A., 2012, Rapid variability of seawater chemistry over the past 130 million years: Science, v. 337, no. 6092, p. 334-336.

Zhang, S., Ague, J. J., and Brovarone, A. V., 2018, Degassing of organic carbon during regional metamorphism of pelites, Wepawaug Schist, Connecticut, USA: Chemical Geology, v. 490, p. 30-44.

Zhang, S., and Planavsky, N., in press, Revisiting groundwater fluxes to the ocean with implications for the carbon cycle: Geology.

Zhang, S., and Planavsky, N. J., 2019, The silicate weathering feedback in the context of ophiolite emplacement: Insights from an inverse model of global weathering proxies: American Journal of Science, v. 319, no. 2, p. 75-104. 